Rehabilitation Research and Training Center for Economic Research on Employment Policy for Persons with Disabilities

Report:

The Health Care Financing Maze for Working-Age People with Disabilities

Nanette J. Goodman

David C. Stapleton

Gina A. Livermore

Bonnie O’Day

Cornell University Institute for Policy Research 
For further information about this paper contact:

Nanette J. Goodman

Cornell University Institute for Policy Research

1341 22nd Street, NW

Washington, DC 20037-3010

tel (202) 223-7670

emailng54@cornell.edu

web www.cuipr.cornell.edu

This report is being distributed by the Rehabilitation Research and Training Center for Economic Research on Employment Policy for Persons with Disabilities at Cornell University.

This center is funded to Cornell University, in collaboration with The Urban Institute (Washington, DC), by the U.S. Department of Education, National Institute on Disability and Rehabilitation Research (No. H133B980038). The contents of this paper do not necessarily represent the policy of the Department of Education, and you should not assume endorsement by the Federal Government (Edgar, 75.620 (b)). The views in this policy brief are not necessarily endorsed by Cornell University or the American Association of People with Disabilities.

The Co-Principal Investigators are:

Susanne M. Bruyère—Director, Employment and Disability Institute, School of Industrial and Labor Relations, Extension Division, Cornell University

Richard V. Burkhauser-Sarah Gibson Blanding Professor and Chair, Department of Policy Analysis and Management, College of Human Ecology, Cornell University

David C. Stapleton—Director, Cornell University Institute for Policy Research 


\title{
The Health Care FinAnCing Maze for Working-Age People WITH DISABILITIES
}

\author{
Nanette Goodman \\ David Stapleton \\ Gina Livermore \\ Bonnie O’Day
}

Acknowledgments: The authors would like to thank Henry Claypool for his comments on an earlier draft. We are grateful for the financial support provided by the U.S. Department of Education, National Institute on Disability and Rehabilitation Research (Cooperative Agreement No. H133B980038). The contents of this paper do not necessarily represent the policy of the Department of Education, and you should not assume endorsement by the Federal Government (Edgar, 75.620 (b)). 


\title{
The Health Care Financing Maze for Working-Age People WITH DISABILITIES
}

\author{
Nanette Goodman, David Stapleton, Gina Livermore, and Bonnie O’Day
}

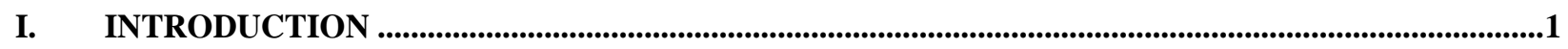

II. SOURCES OF HEALTH CARE FINANCING FOR WORKING-AGE PEOPLE WITH

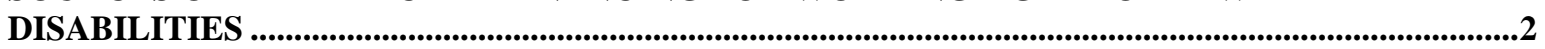

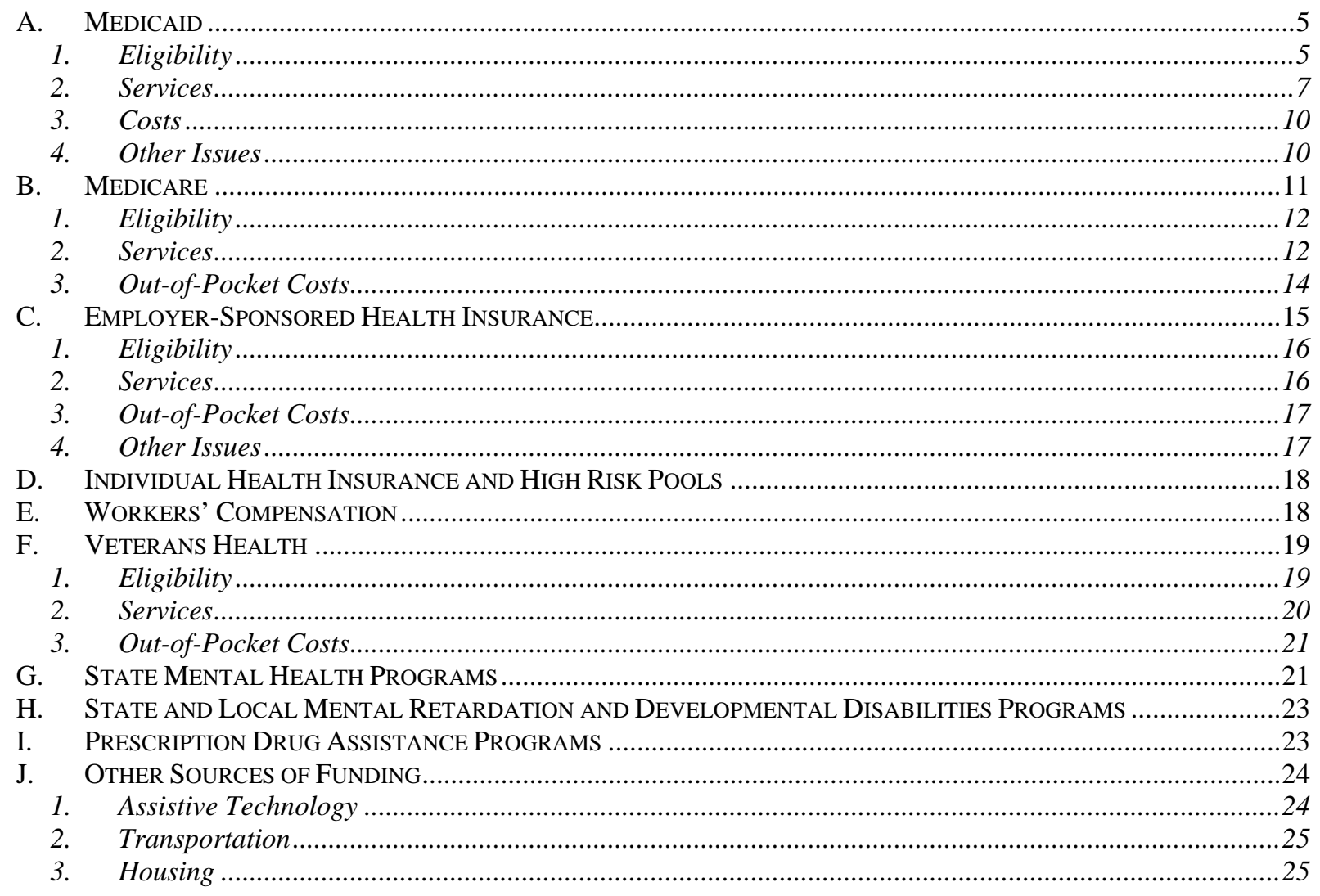

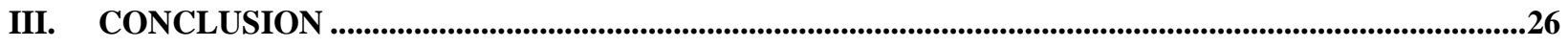

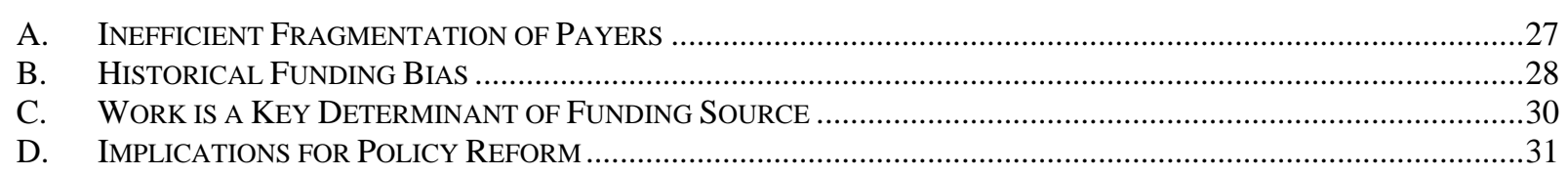

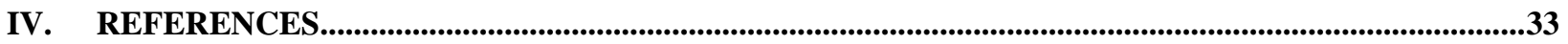




\section{The Health Care Financing Maze for Working-Age People WITH DISABILITIES}

\section{INTRODUCTION}

People with disabilities often require substantial medical services and supports to lead fulfilling lives. Health care expenditures for working-age people with disabilities are almost four times the expenditures of their counterparts without disabilities, about $\$ 8,300$ per year in 2003, compared with \$2,100 per year on average (Medical Expenditure Panel Survey, 2003. These expenditures are covered by a variety of sources: private health insurance, Medicare, Medicaid, and a wide variety of other public health care programs. In 2002, federal expenditures for the health care of people with disabilities totaled an estimated \$102 billion, mostly under the Medicare and Medicaid programs (\$93 billion); states paid an additional \$45 billion (Goodman and Stapleton, 2005).

Despite a high level of public spending on medical care for working-age people with disabilities, the existing health care system is not adequately meeting the needs of this diverse population. Access to services is often determined by age, income, disability type, current work status and previous work experience, and many people face major gaps in needed services.

The health care financing system is complicated by the fact that major financiers of health care for people with disabilities - primarily the states, the federal government, employers, and the individuals and their families -- have, over the years, sought to reduce their own costs by shifting liabilities to each other. As the cost of health care has increased, so has the intensity of costshifting efforts. As a result, the financing of health care for people with disabilities, especially long-term care, and other forms of chronic care services, resembles "a multidimensional, temporally endless game of hot potato, in which beneficiaries and the services they need are regularly tossed from one set of hands to another -- and often fall on the floor in the process” (Vladeck, 2001).

Making matters worse is the fact that access to financing is linked to work status. The public/private health insurance system can make it difficult for people with disabilities to move into and out of the labor market because most private coverage is obtained through employers and most public coverage is linked to a determination of inability to work. Recent initiatives, most notably the Medicaid buy-in programs, authorized by the Balanced Budget Act of 1997 and the Ticket to Work and Work Incentives Improvement Act of 1999, have attempted to break the link between public health insurance eligibility and employment, but have had only moderate success and serve to further complicate the system (Goodman and Livermore, 2004).

From the perspective of meeting the needs of people with disabilities, the root causes of the health care financing system's shortcomings are:

- $\quad$ The financing system is highly fragmented. Diverse sources of funding lead to duplication of services, cost shifting, changes in coverage and service availability as the individual's circumstances change, and a system that is difficult to navigate.

- Funding is oriented toward services other than those that promote independence. Historically, funds that would help people with disabilities gain and maintain independence 
through support for services, equipment and accommodations to address functional limitations, have been relatively limited, and their growth has not kept pace with technological innovations and social changes that have opened up many opportunities for people with disabilities. Instead, most funds are targeted at addressing the acute care needs (through the health insurance system), or the support of individuals deemed unable to work (through disability insurance and welfare payments) or unable to care for themselves (through long-term care insurance and many special programs).

- Work is a key determinant of who pays. For those who work and have employer-sponsored coverage, much of the burden of the individual's health care expense falls on the employer and fellow employees. For those not working, the burden is much more likely to fall on various public programs (most often Medicaid and Medicare) or, in the absence of private or public coverage, the individual. The result is lower retention/hiring incentives for the employer and lower work incentives for the individual.

Much of the research on health care financing for people with disabilities has focused on the Medicaid and Medicare programs. The findings of this research often highlight the inadequacies of those programs in providing appropriate services to address the special needs of people with disabilities. A focus on these large programs, however, obscures the role of other public and private insurers, as well as the role of programs that provide many additional services to this population - all of which add complexity to the system.

The purpose of this paper is to describe the financing system as a whole, including the large public programs, other public and private insurers, and the many other programs that provide additional services. The description of the system highlights structural problems that need to be addressed in order to substantially improve the delivery of health and related services to people with disabilities. In the next section, we describe each source of health care financing for working-age people with disabilities and highlight its implications for service delivery and quality of life. In the concluding section, we describe the key structural shortcomings of the current financing system, assess the extent to which current reform efforts are addressing these shortcomings, and discuss the implications for broader efforts to reform health care financing system.

\section{SOURCES OF HEALTH CARE FinANCING FOR WORKING-AgE PEOPLE WITH DISABILITIES}

Generally when we think of health care, we think of "medical care" with two interdependent components -- the financing system and the service delivery system. The financing system encompasses the sources of funding (the individual, a variety of public programs, employers) and the mechanism for paying the health care bills (involving insurers, managed care organizations, third party administrators, and various other entities). The service delivery system encompasses a wide variety of service providers -- hospitals, clinics, private physicians, and other types of specialty medical service providers - and the processes by which health care is given and received. There is a rich literature about the inadequacies of the service delivery system from the perspective of people with disabilities. Among other findings, this literature notes that: physicians lack adequate knowledge about disabilities (Hanson et al., 2003); providers often have offices and equipment that are physically inaccessible to people with mobility impairments (Iezzoni \& O’Day, 2006); and access is limited for people with communication impairments (Iezzoni et al., 2003). For the purposes of this paper, we focus on 
the financing system, and discuss the service delivery system only as it is affected by the incentives and barriers created by the financing system.

When we discuss health care in the context of disability, the distinction between health care and social services sometimes becomes blurred. Because of the chronic nature of health conditions of many people with disabilities, the interaction between health and other social outcomes is often fundamental to both their medical and economic wellbeing. The health care financing system for the general population focuses on recovery from illness. Such a system is well suited for those for whom wellbeing can be maximized through recovery. In contrast, a financing system designed to help people with long-term functional limitations maximize their wellbeing must consider the financing of services that help address the effects of those limitations on the quality of their lives.

If we define health broadly, as the ability to live independently and participate in the community, a wide range of assistance would be included under the umbrella of health care. For example, evidence suggests that stable housing and supported employment are effective interventions for mental health rehabilitation (Martinez and Burt, 2006, Bond, 2004). Thus, for this population, housing and employment services can be viewed as health services. This explains why, in some instances, Medicaid pays for transportation for medical purposes, coordination of public services (targeted case management), vocational services (sheltered workshops and supported employment), and housing (nursing homes, ICF/MRs, supported living, home modifications).

In the sections below, we describe the sources of health care financing utilized by people with disabilities. For each, we describe who they cover, what benefits they provide, and their relative strengths and limitations with respect to meeting the needs of working-age people with disabilities. In Exhibit 1, we provide a brief overview of these sources. In the discussion of the various sources, we include a sample of the sometimes arcane details of eligibility or service provision to illustrate the complexity and fragmentation of the system. The information provided only begins to scratch the surface of the complexity of this system. It is important, however, not to brush past these details, because they often set up the real life trade-offs that people with disabilities face when trying to manage the economic and health-related risks that are fundamental to their quality of life. 
Exhibit 1. Overview of Health Care Coverage for People with Disabilities

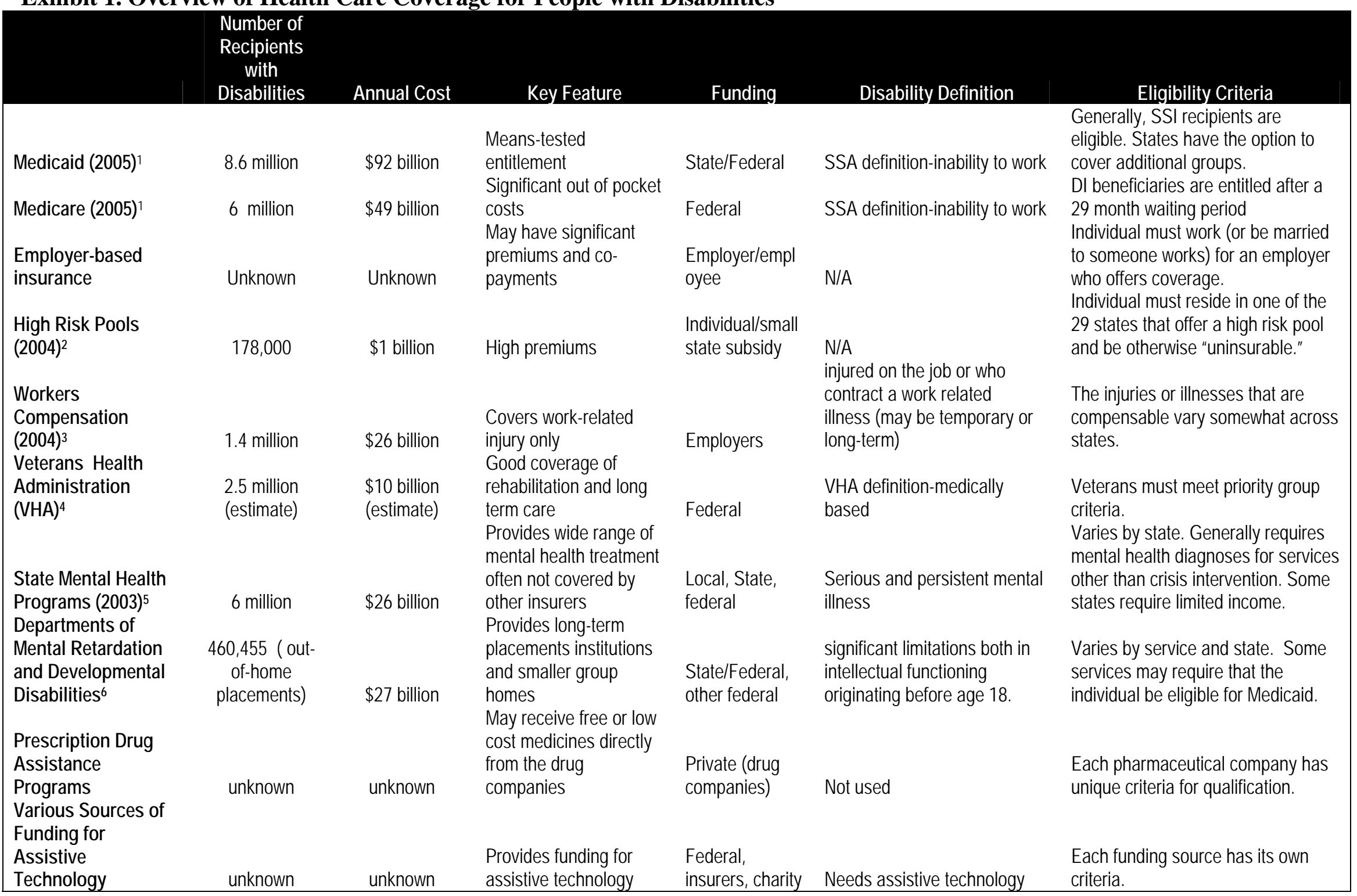

Sources: 1) CMS 2005; 2) Abbe, 2006; 3) Number of Recipients is authors' calculation based on 124,685,000 covered workers (Sengupta et al., 2006) and 1.1\% of covered workers had a claim (DiDonato \& Brown, 2006). Expenditures (Sengupta et al,. 2006); 4) Authors' calculation of VHA enrollment and costs attributable to people with disabilities based on data from National Center for Health Statistics, 2006, Table 142. 5) Lutterman et al., 2006; 6) Rizzolo et al. 2004 


\section{A. MEDICAID}

Medicaid is one of the largest providers of health insurance to people with disabilities. In 2002, it covered 8.6 million people with disabilities at a cost of $\$ 92$ billion (CMS, 2005). ${ }^{1}$ It is widely viewed as the most comprehensive health insurance for people with disabilities because of its broad coverage of mental health services, long term care, personal assistance, durable medical equipment and other services. Nevertheless, access to care is limited by income, asset and other eligibility rules, low reimbursement rates leading to limited physician participation, and variation in covered services by state. Most notably, eligibility for Medicaid generally requires impoverishment.

Medicaid is a means-tested entitlement program. Each state designs and administers its own program under federal guidelines and the program is financed jointly by federal and state governments. The federal government contributes matching payments to states ranging from 50 percent to 83 percent based on each state's per capita income, giving states with lower per capita income a higher matching rate in an effort to equalize states' ability to fund health care services. $^{2,3}$

\section{Eligibility}

In order to qualify for Medicaid, an individual must meet financial and non-financial requirements. The non-financial requirements include "categorical eligibility", immigration status and residency. The financial requirements include income and resource limits.

The federal Medicaid statute identifies over 25 different eligibility categories for which federal matching funds are available. These statutory categories can be classified into five broad coverage groups: children; pregnant women; adults in families with dependent children; individuals with disabilities; and the elderly. Thus, regardless of income, childless adults are generally not eligible for Medicaid coverage. In addition to meeting the categorical eligibility requirements, an individual must be either a U.S. citizen or a legal immigrant who entered the United States prior to 1996, and must reside in the state offering the Medicaid coverage.

Within each category, the federal government mandates coverage of certain groups and states have the option of extending coverage to other defined groups. For many people with disabilities, eligibility is tied to receipt of Supplemental Security Income (SSI). Federal law requires most states to provide coverage to all SSI recipients. Eleven states, known as 209(b) states, are allowed to limit Medicaid eligibility even for people who are SSI eligible by applying a more restrictive definition of disability or lower resource and income standards. ${ }^{4}$ States must also

\footnotetext{
${ }^{1}$ This figure includes only those people with disabilities who are eligible for Medicaid because of their disability. There are expenditures of an estimated \$19 billion for people with disabilities who qualify for Medicaid because of their TANF eligibility (Goodman \& Stapleton, in press).

${ }^{2}$ By law, the minimum match rate is 50 percent and the maximum is 83 percent. In FY 2007, the highest match rate is Mississippi at 83 percent (Federal Register, 2005).

${ }^{3} \mathrm{GAO}$ found that the formula used to determine the federal matching rate based on per capita income does not consistently narrow the disparity in states' ability to fund health care. (GAO, 2003c)

${ }^{4}$ When the SSI program was enacted in 1972, states were given the option to continue to use the Medicaid eligibility standards they had in place at that time.
} 
cover some groups of former SSI recipients-1619(b) participants ${ }^{5}$ and those who lose their SSI eligibility because of certain increases in Social Security Disability Insurance (SSDI) payments (for example, due to Cost of Living increases in DI, entitlement to disabled widow(er), or entitlement or increases in Childhood Disability Benefits).

States are given the option of covering the following groups:

- Medically Needy or "Spend down": Two-thirds of states allow individuals with incomes that exceed the eligibility thresholds for other Medicaid eligibility categories to qualify for Medicaid by incurring medical expenses that reduce their income ("spend down") to a state determined income eligibility limit. In addition, the eleven 209(b) states are required to allow all aged, blind, and disabled residents to spend-down to Medicaid eligibility levels. In some states, the medically needy group is not eligible for the full range of Medicaid services that are required to be offered to the categorically eligible groups (discussed below). ${ }^{6}$

- Poverty Level Group: States may provide Medicaid to people with disabilities with incomes up to 100 percent of the federal poverty level (FPL).

- State Supplementary Payment Group: In some states, anyone receiving an SSI state supplemental payment is eligible for Medicaid.

- Special Income Threshold for Long Term Care Eligibles: Many states provide Medicaid to individuals with incomes below 300 percent of the SSI income threshold who meet the "nursing home level of care" criteria established by the state. These individuals may be nursing home residents or may be living in the community and receiving home and community based services.

- Employed People with Disabilities: 32 states have exercised the authority granted by the Balanced Budget Act of 1997 and the Ticket to Work and Work Incentives Improvement Act of 1999 to expand eligibility to people with disabilities whose earnings would make them ineligible for other Medicaid categories (CMS, 2005). The income and asset criteria vary substantially by state (Goodman \& Livermore, 2004).

Although the spend-down provision allows people with higher levels of income to qualify for Medicaid benefits, the process can be difficult and disruptive. The spend-down process was designed for people who have one-time catastrophic costs or long-term nursing home costs, but for people with disabilities who have chronic catastrophic costs, the program offers only intermittent coverage. Such individuals must regularly "spend-down” to Medicaid eligibility levels by incurring high medical bills which reduce the individual's income below the state-

\footnotetext{
${ }^{5}$ SSI recipients receive a cash benefit computed as the difference between the Federal Benefit Rate (\$623 per month for an individual and \$934 per month for a couple in 2007) and their countable income. When earnings are significant enough to reduce the cash benefit to $\$ 0$, the recipient is eligible to retain Medicaid eligibility until their gross income exceeds a "threshold" computed as total value equal to twice the value of the maximum SSI benefit (including state supplemental benefits) plus mean Medicaid benefits plus publicly-funded attendant care benefits in the state for working-age SSI recipients. This 1619(b) threshold varies by state and ranges from $\$ 1,847$ per month (\$22,174 per year) in Tennessee to $\$ 4,367$ per month $(\$ 52,407$ per year) in Connecticut Also, some states allow individuals with medical expenses that are above the state SSI means to use their own expenses, rather than the state mean, to determine the threshold.

${ }^{6}$ For example, in Florida and Iowa individuals in this category are not eligible to receive long-term care services. New Jersey does not offer hospital or pharmacy coverage for this group.
} 
determined income eligibility limit (medically needy income level). For example, assume the state’s medically needy income level is $\$ 450$ per month. ${ }^{7}$ An individual with a $\$ 650$ monthly income would have a monthly spend-down of (\$650-\$450) or \$200. If the state has opted to use six months as the “budget period” for the program, the $\$ 200$ is multiplied by the state’s budget period of six months for a total spend-down requirement of $\$ 1,200$. Once the individual has incurred medical bills totaling more than $\$ 1,200$ (paid or unpaid), he or she is covered by the Medicaid program for the remainder of the budget period. Any expenses related to health care can be counted toward medical expenses, including health insurance premiums and co-payments, doctor bills, mental health bills, dental bills, home health care, prescriptions drugs, eyeglasses and optometry bills, over-the-counter drugs, medical transportation and others. Going through this process once, as for people with one-time catastrophic costs, is difficult enough, but going through this process every budget period is extremely disruptive.

The number and variety of details required to determine Medicaid eligibility are astounding. For example: It is straightforward to say that most Medicaid eligibility categories require that the applicant has low income and few assets. But, what is considered income? What are considered assets? With respect to income, both SSI and Medicaid count only certain types and certain amounts of income when determining eligibility. Also, the programs count only the portion of spousal or parental income that is left after they subtract amounts to cover the basic needs of non-disabled family members. This process, known as deeming, can vary depending on whether the individual is in an institution, using a Home and Community Based Service (HCBS) waiver, or using standard Medicaid-covered services. To complicate matters further, each state has the flexibility to create less restrictive income counting methodologies, the impact of which can be substantial in terms of who can and cannot qualify for the program.

Counting assets is equally complicated. SSI and most state Medicaid programs require that recipients have assets valued at no more than $\$ 2,000$. The programs generally exclude from this calculation a home (regardless of value) and (within limits) such things as a car, household goods, surrender value of life insurance, burial funds and property essential to self support (O’Keeffe, 2004). States have the option to exclude additional assets. Because Medicaid can be such a valuable benefit, especially for people with high-cost, long-term care needs, individuals have strong incentives to meet the asset criteria by transferring their personal assets to other individuals or entities. A set of rules govern the transference of assets, and states may impose penalties on recipients who have improperly transferred assets in order to make their assets appear low enough to qualify for Medicaid. In response, attorneys have developed a specialty known as "Medicaid estate planning" to assist potential recipients in navigating the program complexities and maximizing their benefits.

\section{Services}

The federal government mandates that Medicaid programs cover a core set of services and gives states the option of covering others. These mandatory and optional services are presented in Exhibit 2.

\footnotetext{
${ }^{7}$ Each state sets its own medically needy income standards, not to exceed 133 and 1/3 percent of the state's prewelfare reform AFDC payment levels. Standards range from \$108 in Arkansas to \$600 in Rhode Island (National Association of State Medicaid Directors, 2002).
} 
With a few exceptions, Medicaid is required to provide the same "amount, duration and scope" of services to all categorically needy eligibility groups. ${ }^{8}$ It is important to note that the individuals who qualify as medically needy are not considered categorically eligible for Medicaid and thus, states may offer a less comprehensive package of services to people qualifying for Medicaid in the medically needy category. ${ }^{9}$

\section{Exhibit 2. Mandatory and Optional Medicaid Services}

\begin{tabular}{|c|c|}
\hline Mandatory Services & Optional Services \\
\hline \multicolumn{2}{|l|}{ Acute Care Services } \\
\hline $\begin{array}{ll}\text { - } & \text { Physicians' services } \\
\text { - } & \text { Laboratory and x-ray services } \\
\text { - } & \text { Inpatient hospital services } \\
\text { - } & \text { Earpatient hospital services } \\
& \text { treatment (EPSDT) services for individuals } \\
& \text { under } 21 \\
\text { - } \quad \text { Family planning services and supplies } \\
\text { - } \quad \text { Federally-qualified health center (FQHC) } \\
\text { - } \quad \text { Rural health clinic (RHC) services } \\
\text { - } \quad \text { Certified nurse practitioner services }\end{array}$ & $\begin{array}{l}\text { - } \quad \text { Prescribed drugs } \\
\text { - } \quad \text { Medical care or remedial care furnished by } \\
\text { - } \quad \text { Diagnosed practitioners under state law } \\
\text { - } \quad \text { rehabilitative seening, preventive, and } \\
\text { - } \quad \text { Dental services } \\
\text { - } \quad \text { Physical therapy and related services } \\
\text { - } \quad \text { Prosthetic devices, Eyeglasses } \\
\text { - } \quad \text { TB-related services } \\
\text { - } \quad \text { Primary care case management services } \\
\text { Other specified medical and remedial care }\end{array}$ \\
\hline \multicolumn{2}{|l|}{ Long-Term Care Services } \\
\hline $\begin{array}{l}\text { Institutional Care } \\
\text { Nursing facility (NF) services for individuals } 21 \\
\text { or over }\end{array}$ & $\begin{array}{l}\text { Institutional Care } \\
\text { - Intermediate care facility for individuals } \\
\text { with mental retardation (ICF/MR) services } \\
\text { - Inpatient and nursing facility services for } \\
\text { individuals } 65 \text { or over in an institution for } \\
\text { mental diseases (IMD) } \\
\text { - Inpatient psychiatric hospital services for } \\
\text { individuals under age } 21\end{array}$ \\
\hline $\begin{array}{l}\text { Home and Community Based Care } \\
\text { Home health care services (for individuals } \\
\text { entitled to NF care) }\end{array}$ & $\begin{array}{ll} & \text { Home and Community Based Care } \\
\text { - } & \text { Case management services } \\
\text { - } & \text { Respiratory care services for ventilator } \\
& \text { dependent individuals } \\
\text { - } & \text { Personal care services } \\
\text { - } & \text { Private duty nursing services } \\
\text { - } & \text { Hospice care } \\
\text { - } & \text { Services furnished under a PACE program } \\
\text { - } & \text { Home- and community-based (HCBS) } \\
& \text { services }\end{array}$ \\
\hline
\end{tabular}

Source: Sommers et al., 2005.

\footnotetext{
${ }^{8}$ There are two exceptions: Early Periodic Screening, Diagnosis and Treatment (EPSDT) must be covered for children but do not need to be available to adults, and 2) States may request "waivers" to pay for otherwiseuncovered home and community-based services (HCBS) for Medicaid-eligible persons who might otherwise be institutionalized. (Work World n.d.)

${ }^{9}$ According to the National Association of State Medicaid Directors (2002), ten states offer a less comprehensive set of Medicaid benefits under their medically needy programs than in their standard Medicaid programs.
} 
The strengths and weaknesses of Medicaid can be seen in its coverage of services that are particularly valuable to people with disabilities, including the following:

Mental Health Services: States may offer a wide array of community mental health services and other supports that focus on rehabilitation and recovery for people with mental illness. This option, known as the Medicaid Rehabilitation Option, allows states to provide services such as basic living-skills training, social-skills training, residential support services, employmentrelated services, certain educational activities, certain social and recreational activities, peer services, family education, substance abuse services, case management and assertive community treatment. Although all states are using the Medicaid Rehabilitation Option, the range of services varies significantly from state to state (Bazelon, 2003).

Assistive Technology and Durable Medical Equipment: Medicaid-eligible individuals under age 21 have access to a wide range of assistive technology through the Early Periodic Screening Diagnosis and Treatment program (EPSDT), a benefit required to be provided in all states. For people age 21 and over, coverage for durable medical equipment and other assistive technology is an optional Medicaid benefit. There are substantial differences across states in the types of devices and equipment that are covered and the circumstances under which they are provided. Generally, Medicaid will cover a technology only if it is deemed "medically necessary," a term whose definition varies across states. Given the differences in how Medicaid programs treat individuals before and after age 21, it is possible that an assistive technology that is covered for a person before age 21 (under EPSDT) may be deemed no longer medically necessary when that same person turns age 21 (NCD, 2000).

Long-Term Care: Long-term nursing home care is a mandatory service for Medicaid programs. Although Intermediate Care Facilities for Persons with Mental Retardation (ICF/MR) is an optional service, it is covered in all states. States have the option to develop home and community based waivers (1915(c) waivers) to serve certain groups who would otherwise be eligible for institutional care (nursing home or ICF/MR) including people with physical disabilities, mental retardation, developmental disabilities and certain specific illness or conditions (HIV/AIDS, traumatic brain injury, and children with special health care needs). Under these programs, the federal government waives certain Medicaid rules and allows states to offer these populations services not available to all Medicaid recipients and to limit the number of people that can access these enhanced benefits. In 2001, there were 229 waiver programs serving 833,000 Medicaid beneficiaries (Reester et al., 2004). Every state except Arizona has at least one MRDD waiver and most states have waivers for the elderly and/or people with physical disabilities.

Currently, home and community based waivers are the principal source for funding home and community based services for people with disabilities. They offer states the flexibility to develop and implement alternatives to placing Medicaid-eligible individuals in institutional settings. There are, however, several notable limitations:

- Although nursing home care and ICF/MR placement are entitlements under Medicaid (i.e., everyone who meets the eligibility criteria is entitled to services), the number of people 
served by home and community based waivers is capped, and in many states there are long waiting lists. ${ }^{10}$ This leads to an "institutional bias" in the way Medicaid dollars are allocated.

- Few states have waivers for mental health services because the waiver must be budgetneutral to the federal government. In other words, the state must make the case that the home and community based services will cost no more than the institutional services that they are replacing. The federal government does not share in the cost of providing institutional care to people with mental illness (such care is covered entirely by state dollars) thus, it is difficult to argue budget neutrality.

- Eligibility for waivers requires that the applicant meet the medical definition of the group covered by the waiver (e.g., people with Mental Retardation and Developmental Disabilities (MR/DD), physical disabilities, traumatic brain injury (TBI), and the elderly) plus meet the institutional level of care requirement. For example, in states with a TBI waiver a low income individual with TBI may receive waiver services where an individual with identical functional needs but a different diagnosis (such as cerebral palsy) will not have access to those services.

The Deficit Reduction Act of 2005 created a new state option for states to provide all HCBS waiver services without needing to get a waiver to both seniors and people with disabilities up to 150 percent of FPL; there is no requirement that eligible beneficiaries require an institutional level of care; requires states to establish more stringent eligibility criteria for institutional services than for home and community based services; and permits states to cap enrollment, maintain waiting lists, and offer the option without providing services statewide. The statute became effective in January 2007. It is too early to know how states will respond to the new option.

\section{Costs}

States are prohibited from charging premiums to most categorically eligible Medicaid beneficiaries, but may require premiums from individuals covered under the buy-in programs and from medically needy beneficiaries. Children, pregnant women, and elderly and disabled beneficiaries who receive SSI cash assistance cannot be charged co-payments. However, "nominal" cost sharing is permitted for other groups, for some services. For example many states require a copayment of between $\$ 1$ and $\$ 3$ per physician visit and between $\$ .50$ and $\$ 3$ to fill a prescription (Kaiser Family Foundation 2005). It is up to the provider to collect the cost sharing amount from the beneficiary. Generally, providers may not deny services if a recipient is unable to pay the cost sharing amount and providers are not reimbursed by the state if their collection efforts fail.

\section{Other Issues}

Medicaid Managed Care: In response to concerns raised during the 1980s that fee-for-service incentives were leading to uncoordinated care, duplication of services and higher-than-necessary health care utilization and costs, in the early 1990s, many state Medicaid programs adopted

\footnotetext{
${ }^{10}$ A 2002 survey with responses representing 171 waivers found that 69 of those waivers had waiting lists. Based on the 41 programs from which states reported the length of the waiting lists, MR/DD waivers had average 19-month wait for services and waiver programs for the elderly and people with physical disabilities had average wait times of between 9 and 10 months (Reester et al., 2004)
} 
managed care financing and service delivery arrangements as a means of addressing these inefficiencies. Disability advocates raised concerns that managed care would decrease access to needed specialty services and threaten health outcomes, especially for those with significant health care needs. But after a decade of experience and research, the impact of Medicaid managed care on working-age people with disabilities is not well understood (Ireys et al., 2002).

Medicaid managed care for people with disabilities varies across states. In most states, enrollment in managed care is voluntary for people with disabilities, although it is mandatory for other Medicaid populations. In recent years, several states have expanded mandatory enrollment to include the SSI disabled population. Some states have an automatic enrollment process with an "opt out" provision (Center for Health Care Strategies 2006). While several states enroll people with disabilities in plans designed exclusively for people with disabilities, most enroll beneficiaries with disabilities in mainstream managed care programs designed for the general Medicaid population. Some states include all Medicaid services in the capitated programs, although most carve out benefits such as pharmacy, behavioral health and long-term care, and pay for these benefits outside of the capitation rate (Regenstein \& Shroer, 1998). ${ }^{11}$

Medicaid Buy-In: The 1999 Ticket to Work and Work Incentives Improvement Act (Ticket Act) expanded state authority originally granted under the 1997 Balanced Budget Act (BBA) to provide Medicaid coverage to working people with disabilities who, because of income and assets, would not otherwise qualify for Medicaid coverage. Both the BBA and the Ticket Act authorized states to charge premiums for this coverage, and thus, allow working individuals with disabilities to "buy in" to Medicaid.

As of March 2005, 32 states had implemented Buy-in programs. Collectively, these programs are serving approximately 79,000 people with significant disabilities. States have wide latitude in designing the programs and, as a result, each program has its own income eligibility criteria (including income limit treatment of spousal income, income counting methodology), asset limits, premium and cost sharing provisions.

The primary rationale behind these programs is to de-link health insurance from SSDI/SSI eligibility and to provide medical supports in ways that promote employment. The programs have had some success in achieving these goals, but may be limited by restrictive program income and asset limits and other program eligibility criteria (Goodman \& Livermore, 2004).

\section{B. MEDICARE}

Medicare covers approximately six million disabled beneficiaries at a cost of $\$ 36.3$ billion per year (CMS, 2004). For people under age 65, eligibility for the program is closely tied to receipt of SSDI. Thus, Medicare provides health insurance coverage for people who have at one time had an attachment to the workforce (i.e., worked in jobs covered by Social Security for an adequate number of qualifying quarters), and have met the SSA definition of disability. ${ }^{12}$

\footnotetext{
${ }^{11}$ Although the most recent, comprehensive study of Medicaid managed care is from 1998, according to a study by the National Academy of State Health Policy, all except one managed care program that existed in 2002 were implemented prior to 1998 (Kaye, 2005). In recent years, several states have changed enrollment of the Medicaid SSI population in managed care from voluntary to mandatory.

${ }^{12}$ SSA defines disability as the presence of a physical or mental health condition expected to last 12 months or longer that renders the individual unable to engage in substantial gainful activity, or is expected to result in death.
} 
Medicare's hospital insurance program (Part A) is financed through a separate Medicare Trust Fund financed through employer contributions and payroll taxes. Medicare Part B, which covers physician services, draws on a combination of federal general revenues and premium payments by beneficiaries.

\section{Eligibility}

Medicare provides health insurance to people with disabilities who are entitled to SSDI. In most cases, however, these individuals must wait five months after they are determined to be eligible for SSDI before they receive SSDI benefits, and another 24 months before they become eligible for Medicare benefits. ${ }^{13}$

During the waiting period for Medicare coverage, people may be: eligible for continued health insurance through their employer (perhaps with a high premium), insured through a spouse, enrolled in Medicaid (if they meet the income and asset requirements), or uninsured. Between one-quarter and one-third of the 1.26 million SSDI beneficiaries in the two-year waiting period are uninsured (Riley 2006, Dale and Verdier 2003) and often have limited access to medical care (Riley 2006)

Under the Ticket Act, an individual who returns to work may continue receiving Medicare benefits for up to 93 months after their SSDI benefits cease.

\section{Services}

The Medicare statute entitles all beneficiaries to the same benefit package, which encompasses all "reasonable and necessary" items and services. The statute sets forth the broad categories of benefits covered by Medicare but neither the statute nor the federal regulations governing the program provide an all inclusive list of the specific items and services that are "reasonable and necessary for the diagnosis and treatment of illness or injury or to improve the functioning of a malformed body member” (Social Security Act XVIII).

Medicare coverage decisions determine what qualifies as reasonable and necessary. The Centers for Medicare and Medicaid Services (CMS) issues ten to twelve national coverage decisions (NCDs) each year that apply to all Medicare beneficiaries. More than forty private contracting organizations develop the vast majority of coverage decisions, called local medical review policies (LMRPs), which are effective in their local jurisdictions only. Although this system facilitates quicker decisions, these policy variations raise the risk of potential inequities for beneficiaries (Foote et al., 2004) and lead to decisions that are inconsistent with Medicare statute and regulation (Gottlich, 2003).

Medicare's focus on treating illness and improving functioning precludes services that may be needed to maintain function (in the case of rehabilitation) or increase independence (in the case of durable medical equipment). Presented below are examples of coverage rules that affect people with disabilities and illustrate the tension between old notions of disability as being an incapacitating medical condition and new perspectives that view people with disabilities as simply in need of supports that can help them integrate fully into the community.

\footnotetext{
13 There are two exceptions to the 24 months waiting period: People with end-stage renal disease are eligible for Medicare after a three-month waiting period, and people with amyotrophic lateral sclerosis (Lou Gehrig's Disease) are eligible without a waiting period (Social Security Amendments of 1972).
} 
Assistive Technology and Durable Medical Equipment: Medicare's Durable Medical Equipment (DME) coverage policies require that the equipment be used primarily in the home. For example, beneficiaries who have trouble walking may need to use a motorized scooter outside of the home but have difficulty getting it approved because of the primarily-in-the-home requirement.

In addition to the in-home requirement, DME coverage is limited by the definition of medical necessity, which is interpreted to mean that the DME is needed for a "medical purpose" with little or no consideration given to increasing an individual's independence (National Council on Disability 2000). For example, Medicare does not routinely fund shower chairs or grab bars, which may be necessary for an individual to bathe safely and independently, or electronic enlarging equipment necessary for a person to read prescription labels and follow diet directions specific to a disease (National Council on Disability, 2000). Furthermore, Medicare considers sensory loss a "functional and quality of life" issue and not a medical concern (Eichner and Blumenthal, 2003), so eyeglasses and hearing aids are generally excluded from coverage. ${ }^{14}$

Long-Term and Home Health Care: Under Medicare statute, only beneficiaries that are "homebound" are eligible for home health benefits. The rules were designed to minimize abuse of the home health benefit by limiting services to only those individuals whose illnesses and disabilities are so severe that leaving the home would require "a considerable and taxing effort." Under the regulations, beneficiaries receiving home care services may leave home only for brief and infrequent periods, and for approved reasons such as a doctor's appointment or to go to church. After intense lobbying by the disability community, Medicare has created a demonstration project to test the fiscal impact of relaxing these requirements. ${ }^{15}$

Prescription Drugs: Historically, Medicare did not pay for prescription drugs unless they were dispensed as part of an inpatient hospitalization or as part of certain outpatient treatments (e.g., cancer). The Medicare Modernization Act of 2003 (The MMA) created a Medicare drug benefit (Medicare Part D) that went into effect in January 2006. For a monthly premium, beneficiaries are now able to purchase a drug plan from a selection of private prescription drug plans that meet minimum requirements set by Medicare. The standard plan has the following features:

- a $\$ 250$ deductible;

- 25 percent co-insurance for drug costs between $\$ 251$ and $\$ 2,250$;

- 100 percent out-of-pocket spending for drug costs from \$2,251-\$5,100; and

- 5 percent co-insurance, or a co-payment of $\$ 2$ for generics and $\$ 5$ for brand name drugs, for costs above $\$ 5,100$.

In 2006, only a small share of Medicare prescription drug plans nationwide offered the standard drug benefit. Almost all drug plans charge different copayments for covered drugs, rather than

\footnotetext{
${ }^{14}$ Medicare will cover one pair of eyeglasses after cataract surgery.

${ }^{15}$ The David Jayne Homebound Amendment, named after the man who initiated and fought three years for its passage, is part of the Medicare Modernization Act of 2003. The amendment creates a two-year demonstration project in three states serving 15,000 people that will gauge the effect of loosening Medicare rules that require people to stay confined in their homes in order to receive home health services. The U.S. Department of Health and Human Services will collect data on whether the rule change increases Medicare costs and determine the viability of changing the Medicare rules.
} 
the standard 25 percent co-insurance., and more than half of all plans have no deductible. Most plans do, however, have a coverage gap or "donut hole" where the beneficiary is responsible for all or a large share of costs up to some limit. (Kaiser Family Foundation, 2006). Premium and cost-sharing subsidies are available for individuals with incomes below 150 percent of FPL or who are dually eligible for Medicare and Medicaid.

Rehabilitation: Medicare requires that the goal of rehabilitation be to improve or restore functioning. Rehabilitation services intended to maintain function or slow the deterioration of functioning, important goals for people with disabilities, are not covered. For example, services for outpatient occupational therapy, physical therapy and speech therapy are denied unless improvement or restoration of function is expected.

Mental Health: Medicare's coverage of mental and behavioral health services is not as extensive as coverage for other services. It requires the beneficiary to pay 50 percent of costs for outpatient mental health treatment, and places a 190-day lifetime maximum on inpatient psychiatric hospital stays. In contrast, for physical health treatment, beneficiaries only pay 20 percent of costs and there is no limit on the length of hospitalization. Neither the Medicare statute nor an NCD establishes limits on clinician coverage and outpatient mental health services as long as the services provided are medically necessary. However, there exist LMRPs that establish annual maximums on the number of covered visits.

\section{Out-of-Pocket Costs}

Limitations in the Medicare benefit package lead most beneficiaries to incur significant out-ofpocket costs unless they obtain some form of supplemental coverage. The beneficiary is responsible for a deductible for hospital care (\$992 in 2007), ${ }^{16}$ additional costs for extended hospital stays, ${ }^{17}$ Part B premiums (\$93.50 per month in 2007), 20 percent coinsurance for physician services, 50 percent coinsurance for mental health care, as well as 100 percent of costs for services that Medicare does not cover. Medicare has no annual or lifetime cap on out-ofpocket spending. Because of these cost sharing provisions, people with higher health care needs are exposed to higher out-of-pocket costs.

As shown in Exhibit 3, 22 percent of disabled Medicare beneficiaries have no supplemental coverage, compared with 7 percent of elderly beneficiaries. The exhibit also highlights the importance of Medicaid in providing supplemental coverage for people with disabilities- 46 percent of disabled Medicare beneficiaries also have Medicaid, compared with 9 percent of elderly beneficiaries.

\footnotetext{
16 Most Medicare beneficiaries do not pay a premium for Part A services since they have 40 quarters of Social Security-covered employment. However, seniors and certain persons under age 65 with disabilities who have fewer than 30 quarters of covered employment may obtain Part A coverage by paying a monthly premium set according to a formula in the Medicare statute at $\$ 410$ for 2007. In addition, certain disabled persons with 30 or more quarters of covered employment, are entitled to pay a reduced premium of \$226 (Center for Medicare Advocacy, 2006)

${ }^{17}$ The Part A deductible is the beneficiary's only cost for up to 60 days of Medicare-covered inpatient hospital care. However, for extended Medicare-covered hospital stays, beneficiaries must pay an additional \$248 per day for days 61 through 90 in 2005, and \$496 per day for hospital stays beyond the 90th day in a benefit period. (Center for Medicare Advocacy, 2006).
} 
Exhibit 3. Supplemental Coverage for Medicare Beneficiaries, 2003

\begin{tabular}{|l|r|r|}
\hline Form of Supplemental Coverage & Disabled & Elderly \\
\hline Employer-Sponsored Insurance & 15.0 & 34.9 \\
Medigap insurance & 6.3 & 32.6 \\
Medicaid & 45.7 & 8.6 \\
Medicare Managed Care & 7.8 & 14.8 \\
Other Public Sector & 3.0 & 1.8 \\
None (Medicare only) & 22.3 & 7.2 \\
\hline
\end{tabular}

Source: Medpac, 2006

Although Medigap policies are an important source of supplemental coverage for the elderly, they are often not available to people with disabilities. Medigap policies are regulated by federal and state law. Federal law guarantees Medicare beneficiaries age 65 and over the right to buy a Medigap policy for six months after Medicare eligibility (known as the open enrollment period) but does not make the guarantee to people under age 65 who are on Medicare because of a disability. However, 22 states have their own guaranteed issue laws which require insurance companies to have at least one type of Medigap plan available to people with disabilities.

\section{EMPLOYER-SPONSORED HEALTH INSURANCE}

Needless to say, eligibility for employer-sponsored coverage is strongly tied to work status. But not all employers offer coverage and availability varies by size of employer and sector. Even employers that do offer coverage tend to require a waiting period and often do not cover parttime workers. Although there are mechanisms to maintain coverage for individuals who move in and out of the labor force, these options are time-limited and expensive.

Often insurers determine premiums for a firm using "experience rating” based on demographics, past health care utilization, medical status, and other factors. ${ }^{18}$ Some employers argue that hiring an applicant with a disability will increase the firm's health care premiums (Harrison, 2006) The Equal Employment Opportunity Commission (EEOC) has clearly stated that refusing to hire a qualified applicant who has a disability because of concern about the potential impact on health insurance costs is a violation of the Americans with Disabilities Act of 1990 (Handleman and Bruyere, 2000).

Further, the ADA requires that, if an employer provides health insurance to employees in general, the employer must provide equal access to employees with disabilities. However, the ADA does allow insurers and health benefit plans to make health-related distinctions if the employer can justify the distinction. For example, a health plan that covers all mental disorders except for major depression would violate the ADA unless the employer can show that the plan is not a "subterfuge" to evade the purposes of the ADA but rather is based on sound actuarial principles or related to actual or reasonably anticipated experience (Handleman and Bruyere, 2000).

The cost of care is financed partially by the employer and partially by employee premium payments and other employee cost sharing.

\footnotetext{
${ }^{18}$ In contrast to community rating where the insurer offers the same rate regardless of differences in expected costs among insured groups or people.
} 


\section{Eligibility}

The employer decision to offer health care varies by employer size. Although 98 percent of large firms (over 200 workers) offer health insurance, only 65 percent of smaller firms offer coverage. Availability of insurance varies by other characteristics of the firm as well. For example, firms with a large percentage of part-time workers are less likely to offer insurance and firms with workers that are highly unionized are more likely to offer insurance. Even in firms that offer coverage, not all employees are eligible because of waiting periods or minimum work hours (i.e. part-time employees not covered) ${ }^{19}$ Among firms that offer health insurance, the average waiting period for new employees to become eligible is 1.7 months (Kaiser and HRET 2003). ${ }^{20}$

\section{Services}

Covered benefits under employer-sponsored plans tend to be relatively comprehensive for acute care and other care that is deemed medically necessary. Although most offer mental health benefits, this coverage is often limited.

Medical Necessity: Health plans often include benefits that may not be covered unless they are deemed medically necessary through prior authorization by the health plan or a case manager. This creates three stumbling blocks for people with disabilities. First, most definitions of medical necessity recognize the need to restore functioning following the onset of a disabling conditions but do not recognize the need to maintain or enhance functioning in people with progressive diseases who want to function more independently. Second, the need for these services is often not well understood by those who authorize them (DeJong et al., 2002). Third, there is a great deal of variation in the process and criteria for making the decision of medical necessity (Singer and Bergthold, 2001).

Assistive technology: The interpretation of medical necessity is an issue for durable medical equipment/assistive technology also. Plans may exclude DME from the benefit package, and even when it is included, insurers commonly use narrow coverage standards (NCD, 2000).

Mental health services: The Mental Health Parity Act of 1996 requires parity in annual and lifetime dollar limits between physical and mental illness in plans that provide both types of benefits. However, the Act does not mandate that a plan must provide a mental health benefit and does not prevent a plan from imposing more restrictive service limits (hospital days or outpatient visits) or higher cost sharing requirements for mental health services than on medical and surgical coverage.

A Kaiser survey found almost all (98 percent) of workers with employer-sponsored coverage had inpatient and outpatient mental health coverage, but 74 percent were subject to outpatient visit limits, 64 percent were subject to inpatient limits, 22 percent had higher cost sharing for mental health visits than for physical health services (KFF/HRET 2005).

A large share of those with employer-sponsored coverage have their mental health services "carved out" and managed by some type of managed behavioral health program (estimates range from 60 to 72 percent). The typical behavioral health carve-out manages inpatient, outpatient,

\footnotetext{
${ }^{19}$ In firms that offer coverage, 81 percent of employees are eligible.

${ }^{20}$ The average waiting period varies significantly by employer size from 1.3 months in firms with more than 5,000 workers to 3.5 months in firms with 3-9 workers.
} 
residential, and intensive outpatient services but does not cover prescription drugs, which are paid for under the general medical benefit. In effect, prescription drugs are "free" inputs to the specialty mental health delivery system, and carve-out vendors have a strong economic incentive to substitute drug treatments for other mental health services when possible. They do this by making it easier for patients to obtain referrals for medication management and psychopharmacology than referrals for psychotherapy. The evidence to date suggests that drug spending has increased under carve-out arrangements with private insurance plans when compared with integrated delivery systems.

\section{Out-of-Pocket Costs}

In 2005, the cost of individual plans averaged \$4,024 per year with employees paying \$610. The cost of family plans averaged $\$ 10,880$ per year with employees paying $\$ 2,712$. For individuals, the specific costs can vary by type of coverage (fee for service, HMO, PPO), breadth of coverage, and the level of coinsurance and deductibles. In addition, nearly all workers pay a copayment at the time of service, and over half pay a deductible before any health care is covered (Kaiser and HRET 2005).

\section{Other Issues}

There are two notable federal laws that have provisions that are important to people with disabilities with respect to employer-sponsored coverage:

Health Insurance Portability and Accountability Act of 1996 (HIPAA): HIPAA provides for health insurance portability between employers by the following regulations:

- Limiting exclusions for preexisting medical conditions-An insurer may not exclude an individual's preexisting medical condition from coverage for more than 12 months after an individual's enrollment date. ${ }^{21}$ The plan must give individuals credit for the length of time they had prior continuous health coverage (without a break in coverage of 63 days or more), thereby reducing or eliminating the exclusion period;

- Providing new rights that allow individuals to enroll for health coverage when they lose other health coverage, get married or add a new dependent; and

- Prohibiting discrimination in enrollment and in premiums charged to employees and their dependents based on health status-related factors.

The Consolidated Omnibus Budget Reconciliation Act of 1986 (COBRA): COBRA gives workers who lose their health benefits the right to choose to continue group health benefits provided by their group health plan for limited periods of time under certain circumstances including, among other life events, the onset of a disability. Qualified individuals may be required to pay the entire premium (both the employee and employer contribution) for coverage. Generally, the employer must offer COBRA continuation coverage for 18 months but an individual with an SSA-determined disability can continue coverage for an additional 11 months. Plans can charge up to 150 percent of the premium cost for the extended period of coverage granted due to disability. Group health coverage for COBRA participants is usually more expensive than health coverage for active employees, since usually the employer pays a part of

\footnotetext{
${ }^{21}$ An insurer may exclude preexisting conditions for 18 months for "late enrollees"- those who do not enroll when they are first eligible.
} 
the premium for active employees while COBRA participants generally pay the entire premium themselves. It is ordinarily less expensive, though, than individual health coverage (U.S. Department of Labor, 2005).

\section{INDIVIDUAL HEALTh INSURANCE AND High RisK PoOLS}

Generally, individual health insurance is either unavailable, excludes preexisting conditions or is prohibitively expensive for people with disabilities. In most states, insurance companies can, and do, charge premiums based on the individual's risk factors. Although 20 states have guaranteed issue laws (Lucia \& Pollitz, 2004), there is no guarantee that the coverage will be affordable.

Pollitz et al. (2001) constructed seven hypothetical applicants in, what they termed "less than perfect health" with conditions ranging from hay fever to HIV. ${ }^{22}$ They asked 60 insurance companies how they would respond to each applicant. With the exception of the applicant with HIV who was denied coverage by all companies, most applicants were offered coverage at least some of the time, but the insurance package usually included benefit restrictions, premium surcharges or both. The premiums varied greatly. For example, annual premiums for a 56-year old widow who is “situationally depressed" averaged \$4,056 (including companies that excluded coverage for depression or any mental/nervous disorder) and ranged from $\$ 1,920$ to $\$ 10,992$. Annual premiums for a 62-year old overweight smoker with high blood pressure ranged from $\$ 2,928$ to $\$ 30,048$, with an average of $\$ 9,936$.

Thirty states operate high risk pools which offer coverage to people who are either denied coverage in the individual market or are rated as such a high risk that their premiums are unaffordable. The pools are typically funded by premiums and subsidized with state resources. The pools often have serious shortcomings that mirror those of the private insurance market. For example, all high risk pools have waiting periods for coverage of preexisting conditions (usually six months to a year), premiums tend to be quite high relative to ability to pay, and most require substantial deductibles, coinsurance or copayments (Chollet 2002). In addition, many states cap enrollment to control costs. Only about 100,000 people are enrolled in high risk pools nationwide raising questions about whether these programs are equipped to offer a meaningful coverage option for people who encounter barriers in the private individual market (Pollitz et al. 2001).

\section{E. WORKERS' COMPENSATION}

Employers are generally required to carry worker's compensation insurance that pays for all medical services (with no cost-sharing by the patient) and wage-replacement benefits to compensate workers who are injured on the job or who contract a work-related illness. Most employers are required to offer this coverage to their employees by either self-insuring, buying a private policy or paying in to a state fund. These programs cover 96 percent of wage and salaried employees, but do not cover self-employed individuals (Sengupta et al. 2006).

The workers' compensation system was designed to provide unhindered, timely access to needed medical services. In reality though, there are a variety of barriers to care, including the following:

\footnotetext{
${ }^{22}$ The seven hypothetical applicants were: 24-year old woman with hay fever, 36-year-old man with college knee injury, family with asthmatic child, 48-year-old breast cancer survivor, 56-year-old woman who is situationally depressed, 62-year-old overweight smoker with high blood pressure and a 36-year-old man who is HIV positive.
} 
- The key to eligibility is that the injury is work-related. Although it is straightforward to determine that a fracture resulting from malfunctioning machinery at work is a work-related injury, it is more difficult to determine whether the heart attack of a worker under job stress who is also a smoker, 55 years old, and has a family history of heart disease is job-related. The determinations in these types of cases vary by state (Dembe, 2001).

- Employers and the workers' compensations insurance carriers have extensive control over the choice of medical providers that can be used by claimants to treat their work-related health conditions (Dembe et al., 2002).

\section{F. VETERANS HEALTH}

Military veterans may receive a wide range of health care services through the Veterans Health Administration (VHA). In general, veterans who were disabled during military service or whose income falls below a means-test threshold receive free medical benefits, while other veterans usually pay a portion of the costs associated with the care. The system, which provided $\$ 28$ billion in health care services to over 7.4 million veterans in 2004 (Congressional Budget Office, 2005), is funded by the federal government through the Department of Veterans Affairs.

Beginning in 1995, the U.S. Department of Veterans Affairs (VA) began shifting their health care delivery from a hospital-based model to one that provides a wide range of services based in the community through a network of both VA and non-VA providers. Despite the expansion of the networks, many veterans must travel long distances for care, especially hospital and specialty care (GAO, 2003b).

\section{Eligibility}

The VHA assigns applicants a priority grouping based on income, whether the veteran has a disability, the severity of the disability, and whether that disability is service-related. There are eight priority groups, with the lower-numbered groups receiving higher priority. If funding is not available for all veterans enrolled in the system, then health care benefits may not be offered to those veterans in the lower-priority groups. In 2003, the VA served all veterans in the first seven priority groups and suspended enrollment among veterans in the lowest group.

The VA uses a "service-connected disability rating" to determine the severity of a veteran's disability, which in turn is used to determine the level of health insurance provided. As shown in Exhibit 4, veterans with the most severe service-related disabilities are in priority group 1. Those with significant disabilities that did not develop as a result of military service, known as "catastrophically disabled veterans" are in priority group 4 . If a disabled veteran has a disability that did not develop while in military service, and is not catastrophically disabled, then the veteran will be placed in a priority group depending on when military service occurred, military honors achieved (e.g. awarded the purple heart), and income. ${ }^{23}$

Like SSA, the VA disability assessment is grounded in an approach that equates certain impairments with incapacity to work. The percentage ratings are based primarily on estimates

\footnotetext{
${ }^{23}$ Veterans may qualify for means-tested benefits if their income is either below the means-test threshold or geographically-based benefits threshold, or if their income is above the means-tested threshold but below the geographically-based threshold. For the purposes of co-payments, those veterans with income above the means-test threshold but below the geographically-based threshold may only receive relief from inpatient co-payments, and not co-payments related to other types of services.
} 
made by physicians in 1945 about the average individual's ability to perform jobs requiring manual or physical labor (GAO, 2003).

\begin{tabular}{|l|l|} 
Exhibit 4. Requirements for Eligibility in VA Priority Groups \\
\hline \multicolumn{1}{|c|}{ Priority Group } & \multicolumn{1}{c|}{ Qualifications } \\
\hline Priority group 1 & Veterans with service connected disability rated greater than $50 \%$ \\
\hline Priority group 2 & $\begin{array}{l}\text { Veterans with service-connected disability rated } 30 \% \text { or } 40 \% \\
\text { disabling }\end{array}$ \\
\hline & $\begin{array}{l}\text { POWs/Purple Heart Recipients } \\
\text { Veterans with service-connected disability rated 10\% or 20\% } \\
\text { disabling. } \\
\text { Veterans discharged for a disability that incurred while in military } \\
\text { service }\end{array}$ \\
\hline Priority group 3 & Catastrophically disabled veterans \\
\hline Priority group 4 & $\begin{array}{l}\text { Veterans receiving a VA pension } \\
\text { Veterans eligible for Medicaid benefits } \\
\text { Veterans with income below the VA means-test threshold }\end{array}$ \\
\hline \multirow{3}{*}{ Priority group 6 } & $\begin{array}{l}\text { World War I veterans } \\
\text { Veterans with compensable injuries rated 0\% disabling } \\
\text { Veterans seeking treatment for specific conditions (e.g. exposure to } \\
\text { herbicides while serving in Vietnam). }\end{array}$ \\
\hline Priority group 7 & $\begin{array}{l}\text { Veterans with income above the VA means-test threshold but below } \\
\text { the geographic-adjusted means-test threshold. }\end{array}$ \\
\hline Priority group 8 & $\begin{array}{l}\text { Veterans with income above both the VA means-test threshold and } \\
\text { the geographic-adjusted means-test threshold. }\end{array}$ \\
\hline
\end{tabular}

Source: U.S. Department of Veterans Affairs. n.d.a.

Veterans may simultaneously receive health insurance through Medicare or Medicaid and the VA. In general, if a disabled veteran has other health insurance (including both private and public health insurance), then the VA assumes responsibility for health care related to a serviceconnected injury or disability, while the other health insurance provider is responsible for covering costs related to all other injuries and health needs. In recent years, 42 percent of all veterans were enrolled in Medicare (VA Information Resource Center, 2003).

\section{Services}

The VA offers a benefit package that includes basic health care (inpatient and outpatient medical and surgical care), mental health care (including substance abuse treatment), prescription drugs, and emergency care in VA facilities (and in non-VA facilities in certain conditions). In addition, the benefit package includes services particularly needed by people with disabilities including comprehensive rehabilitative services, home health services and durable medical equipment, adaptive equipment, assistive technology and home modifications.

Most of the care is provided by the VHA's 172 medical centers, 800 ambulatory care clinics, 137 nursing homes, 43 domiciliaries, 206 readjustment counseling centers, 73 comprehensive home care programs, and networks of community physicians.

Housing: The VA has an array of services and initiatives to help veterans recover from homelessness and live as self-sufficiently and independently as possible. These services include:

- $\quad$ aggressive outreach; 
- clinical assessment and referral to needed medical treatment for physical and psychiatric disorders, including substance abuse;

- long-term sheltered transitional assistance, case management, and rehabilitation;

- $\quad$ employment assistance and linkage with available income supports; and

- $\quad$ supported permanent housing.

One-third of the adult homeless population have served in the armed services (U.S. Department of Veterans Affairs u.d.b.). While there is no accurate measure of the number of homeless veterans, it has been estimated that more than 200,000 veterans may be homeless on any given night and that twice as many veterans experience homelessness over the course of a year. Many other veterans are considered at risk because of poverty, lack of support from family and friends, and precarious living conditions in overcrowded or substandard housing. Almost all (97 percent) homeless veterans are male and the vast majority is single. About 45 percent of homeless veterans have mental illness and, with considerable overlap, slightly more than 70 percent have alcohol or drug abuse problems (U.S. Department of Veterans Affairs u.d.b.).

\section{Out-of-Pocket Costs}

There is no premium cost for VA services but copayments are based upon a veteran's priority group status. Disabled veterans in priority group 1 are not required to make co-payments for any service. Other disabled veterans must provide co-payments for certain services. For example, veterans in priority groups 1 , 2, or 3 do not need to make co-payments for long-term care, while veterans in lower priority groups generally are required to make co-payments when receiving this type of health care. Another example of benefit stratification is the medication benefit: veterans in priority group 1 are not required to provide a co-payment for medication, while those in lower groups must make a medication co-payment, unless the medication is related to a service-connected condition. A final example of benefit stratification concerns nursing home care. Veterans with service-connected disability greater than or equal to 70 percent qualify for unlimited nursing home benefits, while those with less severe service-connected disabilities may receive nursing home care (potentially on a limited basis) dependent on the resources available to the VA.

\section{G. State Mental Health Programs}

Historically, individual states, rather than the federal government, have assumed principal responsibility for providing services to people with mental illnesses. As a result, the public mental health system in the U.S. really is a collection of 59 different state and territorial mental health systems, each with its own approach to identifying priority populations and financing and delivering services. One advantage of this state-by-state system is that states and communities are able to tailor their programs to meet the unique needs and environments of the people they serve. However, the system also results in significant disparities across states in the role of institutions as well as the breadth and quality of community-based services (Bianco et al., 2001).

As shown in Exhibit 5, mental health system funding comes from a variety of sources, including state funds, federal mental health block grants, Medicaid and Medicare revenues, and grants for research and demonstrations (Lutterman et al. 2006). In 2004, state mental health agencies controlled the expenditures of over $\$ 27.2$ billion (Lutterman et al. 2006). 
To be served effectively in community settings, people with mental illnesses must have access to a broad range of non-mental health services - housing, income support, employment and education, and treatment for co-occurring medical or substance abuse disorders. The public mental health system is challenged to blend programs and funding streams in a way that provides a comprehensive system of services and supports for this population (Bianco et al., 2001).

Exhibit 5. Sources of Funding for State Mental Health Authority Revenues, 2004

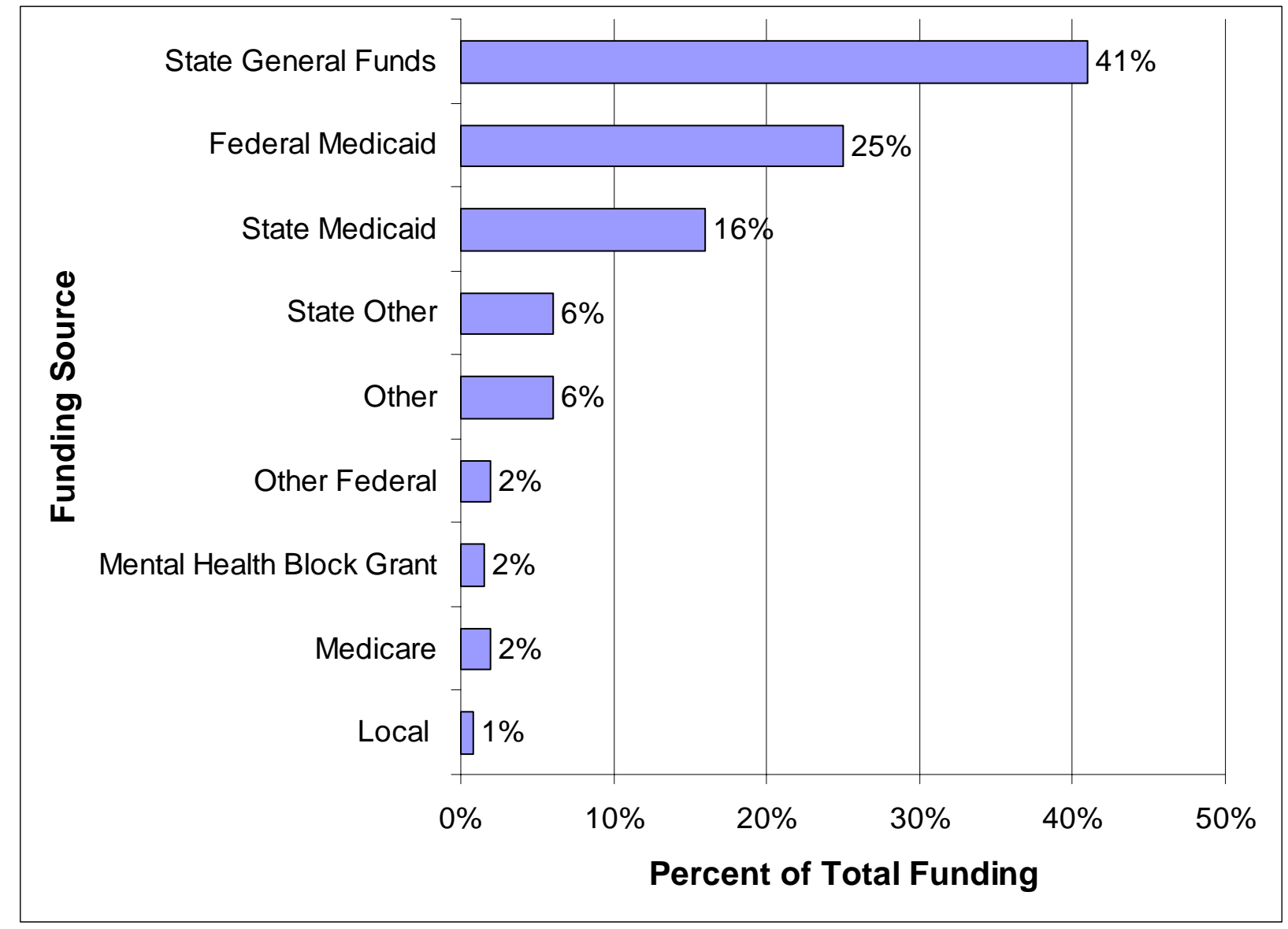

Source: Lutterman et al., 2006.

Medicaid has had an enormous impact on the shape and impact of public mental health care. Medicaid mental health policy has expanded access, fostered consumerism, and created incentives for expansion of community-based providers. It also has dramatically changed the economic rules governing public mental health care, leading state governments to alter their behavior. The result has been a tilting of public mental health care toward Medicaid-covered people and services. As states devote a higher portion of their mental health funds to meeting Medicaid match requirements, states' ability to maintain or expand mental health/substance abuse programs for a growing population of low-income uninsured people is becoming increasingly constrained. Thus, the consequence of the growth in Medicaid spending for mental health over the past 30 years appears to be a reduction in the discretionary funds for states to attend to the traditional safety-net function of the state mental health agency (Frank et al.,2003). 


\section{STATE AND LOCAL MENTAL RETARDATION AND DEVELOPMENTAL DisABilities PRograms}

State and locally-funded programs for people with mental retardation generally serve people who meet the state's diagnostic criteria regardless of income. Mental retardation is usually defined as significantly subaverage intellectual functioning and deficits in adaptive behavior, but the actual application of this definition varies by state. In some states, it is strictly defined as an intelligence quotient (IQ) of 70 or below; in others, more flexibility is permitted. MRDD programs are not entitlements. A state can limit participation on a first-come, first-served basis or by providing services to those with the greatest impairments first and cutting off enrollment when the funding runs out.

The type of services vary by state but generally the MRDD agency provides services coordination, vocational services, habilitation (day program), a range of medical services and assistive technology, personal assistance, household modifications, and residential services. Some services provided by MRDD agencies are reimbursed by Medicaid. An estimated 77 percent of total developmental disabilities long-term care spending is financed by Medicaid (Hemp\& Braddock 2003). The remainder is funded by state and local funds. Despite this shift toward federal financing through the use of Medicaid HCBS waivers and ICF/MR programs, the system is chronically underfunded. In 2002, 36 states reported a total of over 76,000 people with MRDD on formal state waiting lists for residential services and other community-based services (Reester et al., 2004).

\section{Prescription Drug Assistance Programs}

There are several sources of prescription drug assistance for people who are either uninsured or whose insurance does not cover pharmaceuticals, including the following:

Patient Assistance Programs: More than 100 pharmaceutical manufacturers offer Patient Assistance Programs (PAPs) that provide their drugs free or at a discounted price to uninsured and underinsured people. Each pharmaceutical company has specific criteria that must be satisfied in order for an individual to qualify for assistance. Consumers need to apply separately to the manufacturer of each drug they need, although several groups, including the Pharmaceutical Research and Manufacturers of America (PhRMA), have developed web-based systems to streamline the process.

AIDS Drug Assistance Program (ADAP): People with HIV/AIDS can obtain assistance from their state to receive HIV-related medications free of charge. ADAP is a federally-funded program of the Health Resources and Services Administration (HRSA) that provides grants to states. Each state establishes its own program eligibility criteria. All require that individuals document their HIV status. Fifteen states require income to be at 200 percent or less of the FPL for program eligibility. Nationally, more than 80 percent of ADAP clients have incomes at 200 percent or less of the FPL (U.S. Health Resources Services Administration, n.d.).

State-Funded Drug Assistance Programs: At least 31 states have established a state-funded program to subsidize prescription drug expenditures, primarily to low-income elderly and, in about half of the programs, people with disabilities (National Conference of State Legislatures 2005). Each program has its own income eligibility limits and in some cases, asset limits. The definition of disability for the purpose of program eligibility also varies by state. Some states 
restrict eligibility to people who are receiving SSDI, while others use state-developed criteria (GAO, 2000).

\section{OTHER SOURCES OF FUNDING}

\section{Assistive Technology}

The sources of funding for assistive technology are so fragmented that each state has a technology assistance program funded in part under the Assistive Technology Act to help users navigate the system. If the assistive technology is necessary for employment, it may be funded by the state vocational rehabilitation agency. If it is necessary for education, it may be funded by the local school district under the Individuals with Disabilities Education Act (IDEA). Medicaid recipients may receive assistive technology through that program, but access varies by the recipient's age and by state. Although there are a number of different sources for assistive technology, according to the National Council on Disability, "laws and policies that fund assistive technology have gaps that fail to address the needs of many individuals with disabilities” (NCD 2000).

A publication by the Delaware Assistive Technology Initiative provides some insights into the consumer perspective. Intended for consumers, the publication recommends "Be patient and persistent...Keep trying. Be creative and most of all don't give up. In many cases, particularly with insurance, denials can be appealed. Simply regard the denial as a request for additional information” (Delaware Assistive Technology Initiative 2005).

Sources of assistive technology funding include the following (Univ of Washington, 2003):

- Health-related sources--Private Health Insurance/HMOs, Medicare, Medicaid, VA, Tricare, and some High Risk Pools.

- Employment-Related Sources--employers (reasonable accommodation), state vocational rehabilitation agencies and services for the blind, Social Security programs (Plan for Achieving Self-Support, Impairment-Related Work Expenses), and Workers' Compensation.

- Education-related sources--The school systems are required to provide some assistive technology for certain school-age children under IDEA or Section 504 of the Rehabilitation Act of 1973. Most post-secondary schools must provide reasonable modifications in both academic and extra-curricular programs and services to accommodate the needs of students with disabilities. The extent to which this accommodation includes assistive technology varies by institution.

- State Projects funded under the Technology Related Assistance Act for Individuals with Disabilities (Tech Act)—These projects vary by state, but can provide low-interest loans, used equipment banks, funding for technology purchases or assistance advocating for funding from other programs.

- Other Sources of Assistive Technology Funding--Community service organizations (e.g., Elks, Rotary, Soroptomist, Lions Clubs), private bank loans, private trusts and foundations.

Each funding agency has its own criteria to determine eligibility for assistance, and the request for assistance must address the specific criteria used by the particular funding source, otherwise, the request will probably be denied. For example, health insurers will fund augmentative communication devices if they are medically necessary (i.e., if the condition affects the 
individual's ability to communicate symptoms and discuss medical issues with a health care provider, and to otherwise participate in medical decisions). State vocational rehabilitation agencies will fund a device if it affects employability - the applicant must show how job prospects would be improved with the use of an augmentative communication system.

In addition to specific eligibility criteria, each funding agency has its own policies and procedures. For example, Medicaid and many insurance companies require pre-authorization for the purchase of certain types of medical equipment. Medicare does not require pre-approval for most equipment.

\section{Transportation}

The federal government views transport to health care facilities as an ancillary medical service, rather than a goal of the public transit system, and therefore, both Medicare and Medicaid provide emergency transportation. ${ }^{24}$ Medicaid also provides non-emergency medical transportation (i.e. transportation to medical appointments). A number of other federallyfinanced programs provide medical transportation as well, including state-run workers' compensation and rehabilitation programs, home and community-based health services designed to promote independent living, programs financed under the Older Americans Act, and a variety of specialized transport services for veterans and people with disabilities (Raphael 2001). According to one source, there are 62 federal programs that fund transportation (United We Ride u.d).

\section{Housing}

The interaction between housing and our traditional notion of health care is ambiguous. In describing the rationale for including a grant program for Medicaid agencies to develop models of integrated long-term care supports and affordable housing, the Centers for Medicare and Medicaid Services (CMS) explains: "lack of access to either supports or affordable and accessible housing precipitates an at-risk living situation for unnecessary admissions to institutions, decline in physical and mental health, and an overall decrease in the quality of one's life.” (CMS 2004)

The most prevalent and well known type of housing assistance for people with low incomes is the Section 8 Housing Voucher program, which is administered by local public housing agencies with federal funds from the U.S. Department of Housing and Urban Development (HUD). Households with income at or below 50 percent of the area's median income level are eligible for the program, but at least 75 percent of vouchers must go to households with incomes below 30 percent of the area median income.

HUD earmarks some funds specifically for people with disabilities. Section 811 provides housing for people with physical or developmental disabilities, or people with chronic mental illness who are 18 years of age or older and have very low incomes. Adults with disabilities with household incomes at or below 50 percent of the area median income are eligible to participate.

\footnotetext{
${ }^{24}$ By law, Medicare can only reimburse patient transportation to a Medicare-approved medical appointment if the transportation is provided by an ambulance. Ambulance trips are theoretically reimbursable only if the service is needed for the treatment of the illness of injury. Nevertheless, there is evidence that the Medicare program is reimbursing clients and ambulance operators for many trips that could be provided by non-ambulance transportation (Burkhardt 2002).
} 
Under section 811, HUD provides two programs: 1) mainstream rental vouchers similar to Section 8 vouchers; and 2) interest-free capital advances to non-profit sponsors to help finance the development of rental housing such as independent living projects, condominium units, and small group homes that offer voluntary supportive services for people with disabilities. These HUD programs (both Section 8 and Section 811) are not funded adequately to meet the growing demand for low-income and supported housing (Stegman 2002, Technical Assistance Collaborative n.d.).

\section{CONCLUSION}

Although working-age people with disabilities are insured at a rate similar to the general population, a much higher percent rely on public health insurance coverage (Steinmetz 2006) at a cost to states and the federal government of almost $\$ 150$ billion per year. ${ }^{25}$ This does not mean, however, that people with disabilities have access to the services that would help them achieve a reasonable standard of living or become more self-sufficient, given their medical conditions and functional limitations,. Because coverage, cost sharing, and access to providers varies by the insurer, place of residence, and, in some cases, type and cause of disability, it is difficult to quantify the "availability" of services. For example:

- People with disabilities in the general household population are four times more likely than people without disabilities to have special needs that are not covered by their health insurance (28 percent versus 7 percent) and those who have very severe disabilities are almost four times more likely to have inadequate insurance coverage for special needs than people with slight disabilities (40 percent versus 11 percent) (Harris, 2004).

- In a 2003 household survey, one-quarter of non-elderly adults with disabilities reported experiencing trouble finding a doctor who understands their disability (Hanson et al. 2003). ${ }^{26}$

- Over 76,000 people with mental retardation and developmental disabilities were on waiting lists for residential services in 2002 (Reester et al. 2004)

- Nearly half (46 percent) of people with disabilities in the household population have reported going without necessary items such as durable medical equipment and eyeglasses due to cost (Hanson et al. 2003).

- The link between work and eligibility for public insurance is often cited as one of the primary barriers to employment and self sufficiency (Ticket To Work and Work Incentives Improvement Act of 1999).

Of course, increased public funding of current programs would increase access to services, but high projected growth in government expenditures, driven largely by the aging of the baby boom generation and the rapid growth in the cost of health care services (Greenspan 2004), make it unlikely that policymakers will choose to increase access via major increases in funding. There may, however, be good opportunities to improve access to health care without politically unacceptable increases in funding. Such opportunities would need to address structural problems

\footnotetext{
25 In 2002, estimated total federal and state expenditures for the health care of working-age people of disabilities were $\$ 147$ billion (Goodman and Stapleton, 2005).

${ }^{26}$ This finding is similar to the NOD/Harris Survey which found that 25 percent of people with disabilities had trouble finding a doctor who understood their personal health care needs.
} 
in the financing system. Below, we describe three such flaws: inefficient fragmentation of payers; funding oriented toward services other than those that promote independence; and links between employment status and the sources of funding. We then close with a brief discussion of the implications for policy reform.

\section{A. InefFicient Fragmentation of Payers}

The President's New Freedom Commission on Mental Health reported that the safety net for mental health services (i.e., state mental health programs) is "fragmented and in disarray" and facing a "quiet crisis" (Applebaum 2003). In fact, it would be reasonable to apply this statement to the entire system for the financing of health care and related services for working-age people with disabilities. Funding for such services ultimately comes from private resources (i.e., the individual and the individual's family or other personal supporters), and social resources - the resources of the rest of society, primarily those used to pay for health insurance premiums and taxes, but also charitable contributions and volunteer labor. Social resources, and some private resources, are funneled through a complex array of public and private payers -- Medicare, Medicaid, employer-sponsored insurance, individual health insurance, high risk pools, workers' compensation, veterans' health, state and local mental health and mental retardation programs, prescription assistance programs, and a variety of funding sources for assistive technology. Ideally, the system of payers would allocate the available social resources to individuals in a manner that is deemed both equitable by society, and maximizes the well-being of each individual, given the resources available (i.e., is economically efficient). ${ }^{27}$ Our review suggests a very different outcome.

Payers are fragmented in an inefficient manner - a manner that has evolved over decades in a process driven by both market and political forces. Different payers are responsible for different target populations and different services. Each payer has its own mix of interests - those of its funding sources, its target population, and even of the providers it pays. As a result of these disparate interests, resources are allocated across the working-age population of people with disabilities in a manner that is often viewed as arbitrary, inequitable, and inefficient. Some people with high health care needs have very limited ability to draw on social funding to pay for such care (e.g., SSDI beneficiaries who are in their Medicare waiting period and who do not have private insurance or Medicaid), while other very similar individuals have substantial coverage (e.g., a new SSDI beneficiary who also qualifies for Medicaid, via SSI). Others cannot obtain services or equipment that might improve the quality of their lives substantially (e.g., a Medicare beneficiary who needs personal assistance services), but have full access to other services that might have little value to them (e.g. kidney dialysis or an organ transplant). Some forego or postpone needed care because of lack of funding (Hanson et. al., 2003). The financing system does not support extra services that people with disabilities often need. For example, although people with disabilities and chronic conditions use multiple physicians, ${ }^{28}$ most payment systems do not pay providers for the time they spend coordinating care with other providers (Anderson \& Knickman, 2001). Communication between the patient and clinician can have a

\footnotetext{
${ }^{27}$ An allocation of resources is economically efficient if no re-allocation exists that would make one person in the target population better off without making another person worse off.

${ }^{28}$ An analysis of Medicare claims data suggests that the average Medicare beneficiary with one or more chronic conditions is seen by eight different physicians during a year (Institute of Medicine, 2001).
} 
large impact on health care quality, but the financing system does not provide incentives or compensation for physicians to be competent in disability-related issues.

Significant resources are spent by payers to protect their own interests and shift costs onto each other - resources that might instead be spent on more services, or reducing overall expenditures for such services. This is reflected in the often arcane details of eligibility and service provision for each of these programs. The financing system is further complicated by the fact that a substantial portion of people with disabilities receive funding from social resources through multiple insurers or programs, each with its own coverage rules, co-payments, definitions of medical necessity, and appeals systems. Many individuals also rely on other non-health supports paid for, at least in part, from social resources (e.g., vocational rehabilitation, housing, education, and substance abuse treatment). Although these services can have a significant impact on the individual's health and wellbeing, their funding is not at all integrated with funding for health care. For example, stable housing and supported employment can be valuable inputs into treating mental illness. Funding for these services, for the most part, falls outside the health care financing system as commonly defined.

Examples of cost-shifting abound: Medicare shifts long-term care costs primarily to Medicaid; state and local MRDD and mental health programs shift state-funded services to Medicaid; some people who need long-term care divest themselves of assets so that they will qualify for Medicaid; workers' compensation programs shift costs back to other employer-based health plans and vice versa; and private insurance shifts more and more costs to the consumer and public programs. Rapid growth in the cost of health care is generating rapid growth in efforts to shift the burden of health care, draining resources that might be put to better use under a more well-designed system.

When goods and services are paid for solely by private resources and consumers have adequate resources and excellent information about what they are buying, the invisible hand of the market can lead to an economically efficient and socially acceptable allocation of goods and services. There is, however, a broad consensus that markets alone would not lead to a socially acceptable allocation of health care and related services to working-age people with disabilities, in part for equity reasons (i.e., there is a consensus that resources should be redistributed toward workingage people with acute health conditions, chronic illnesses and long-term impairments), and in part because the technical, idiosyncratic nature of many services makes information itself a scarce resource. Additionally, private health insurers face financial disincentives to cover longterm services and supports and to offer health insurance to those most in need. Private and public health insurance, along with many other public programs, serve the role of allocating social resources to those most in need of health and related services, but there is no invisible hand to ensure that they do so in an efficient and equitable manner. Instead, they evolve through a cumbersome political and bureaucratic process that fails to keep pace with technical developments and social change.

\section{B. HISTORICAL FUNDING BIAS}

The health insurance system was conceived primarily with the intent of reducing the risk of extraordinary expenditures for acute care. That is, its primary focus is to ensure that resources are available to efficiently treat acute conditions and restore health. Disability and long-term care insurance and other programs were conceived as safety nets for people who could no longer work or take care of themselves because of long-term impairments or chronic health conditions. 
Historically, funds that would help people with disabilities live and work in their communities, through support for services, equipment and accommodations to address functional limitations, have been relatively limited. Although documentation is not available, it appears that growth in funding for such supports has not kept pace with technological innovations and social changes that have opened up many opportunities for people with disabilities when such supports are available.

The acute care focus of health insurance is apparent in all health insurance policies and programs except Medicaid. Insurers draw a sharp line between medical and non-medical care, and cover only those services that are deemed to be medical in nature. Most definitions of medical necessity recognize the need to restore functioning but do not recognize the need to maintain or enhance functioning in people with progressive diseases who want to function more independently (DeJong et al., 2002). For example, Medicare specifically excludes services that support functioning or increase independence: rehabilitation is covered only if its goal is to improve or restore functioning rather than maintain function; and eyeglasses and hearing aids are specifically excluded because Medicare considers sensory loss a functional or quality of life issue. Most health insurers provide very limited coverage of long-term care--both communitybased care and institutional care. Medicare does not cover institutional long-term care and has limited coverage for in-home care: it covers skilled nursing services in the home but only if the beneficiary is "homebound."

Mental health coverage also has an acute-care focus. Insurance payments for services to maintain mental health and prevent acute episodes are limited by payment policies. Medicare charges higher co-payments for mental health services than physical health services. Although private insurance has been moving toward parity between mental and physical health services, most policies continue to have significant restrictions on mental health services relative to physical health services.

Substantial social funding is available for non-acute services, but historically, such funding has been largely restricted to those who have such severe impairments and conditions that they are deemed no longer able to work (public and private disability insurance), and/or who are impoverished (Medicaid, SSI, public mental health and developmental disability programs, and many others). Those who receive assistance often live in long-term care facilities, although there has been a substantial effort to place such individuals in non-institutional settings and provide them with home and community based care, mostly under Medicaid waivers. These programs are rooted in an era of paternalism toward people with disabilities (Stapleton et al., 2006).

A strikingly small share of social funding to support working-age people with disabilities is allocated to supports that help such individuals live and work in the community-services, equipment and accommodations that would address their functional limitations and help them participate more fully in work and other social activities. Medicaid does allow broad coverage for services that promote independence and quality of life, but such coverage generally falls in the optional Medicaid categories. Consequently, coverage varies by state, is subject to cutbacks in response to fiscal pressure, and is only available to those who are poor enough to qualify. Further, except under the recently introduced Medicaid Buy-in programs, funding for workingage people with disabilities has been limited to those who have been deemed unable to work and to very low-income individuals with disabilities. Thus, Medicaid funding for such supports might be available if the individual is living in poverty, but is not likely to help the individual escape poverty. Some funding is also available through employment, education, training, housing, food 
and miscellaneous other programs, but in 2002, such programs accounted for only 4.6 percent of federal expenditures to support working-age people with disabilities (Goodman and Stapleton 2006). Of course, cash benefits from private or public disability insurance or SSI could be used to pay for supports, but these programs are intended to help recipients pay for ordinary living expenses, not extraordinary support needs, and support is only available if the program determines that the individual is unable to work.

Medical technology increasingly enables people with very severe disabilities to leave their homes and participate in community life if they have access to the technology or other appropriate supports. A large and growing number of jobs can be performed by people with profound impairments if they have appropriate accommodations, assistive technology or other supports. The rights of people with disabilities to participate in society have been established by federal law (the Americans with Disabilities Act of 1990), but the pace of change in funding priorities that would enable them to do so has been very slow.

Although some care is difficult to find, the system may "overproduce" acute care services, in the sense that the marginal value of the services produced is below the marginal cost of their production. What insured patients pay (i.e., the private marginal cost of production) is far lower than what the service costs to deliver (i.e., the social marginal cost of production), it is generally in the provider's financial interest to deliver more services, not fewer, and providers themselves are usually empowered to make decisions about what services are delivered. Hence, it is not surprising that the marginal value of many services delivered is well below the marginal cost of their production.

\section{WORK IS A KEY DETERMINANT OF FUNDING SOURCE}

The current system essentially assigns people a type of insurance based on a variety of factors, including: employment status and, if employed, the specific job; income; assets; marital status; type and severity of disability; state of residence; and others. Changing any of these characteristics can impact eligibility. For example:

- Increasing income or assets can often result in loss of Medicaid eligibility.

- Job loss often means loss of employer-based coverage. Although COBRA provides former employees an option to keep their employer coverage for 18 months (or longer, if disabled), it is costly for them to do so.

- Choosing community-based care rather than institutional care might limit Medicaid coverage, depending on the availability of waivers.

- Moving from one of the 31 states with a Medicaid Buy-in program to a state without a Buyin or a state with different eligibility criteria can cause a loss of coverage.

The current system, which, for the most part, links eligibility for Medicare and Medicaid to SSDI and SSI eligibility, respectively, is based on the flawed notion that there is a medically determinable line between people who can and cannot work; only those determined unable to work are entitled to cash and health care benefits. The Social Security disability determination system attempts to draw this line. What results is an administratively complex and error-prone system in which: the initial decision can take months to develop; the initial decision is substantially affected by where the application is filed and which examiner happens to review it; almost one-third of those who receive benefits receive them only after appealing an initial denial; 
applicants often wait over a year for a final decision; and many people with very significant disabilities are denied benefits (Stapleton, 2004).

The linking of public health insurance to inability to work via SSDI and SSI distorts work incentives for people with disabilities who can work, especially if their job opportunities are limited to jobs that do not offer health insurance (such as people who can work only part-time or intermittently or in low wage service sector jobs) or that offer health insurance but without coverage for critical services. There is ample evidence that the design of eligibility of the income support programs discourages people with disabilities from working, although it is difficult to attribute those findings directly to the financing of health care. ${ }^{29}$

\section{IMPLICATIONS FOR POLICY REFORM}

In this paper, we focused on the shortcomings of the financing system for the health care of working-age people with disabilities. The financing system for this population group is, of course, substantially integrated with health care financing for the rest of the population working-age adults without disabilities, children and youth, and elderly adults. Many, if not all, of the issues we have raised for working-age people with disabilities apply to other groups in varying degrees. It seems unlikely that substantial reforms to address problems for the financing of care for working-age people with disabilities will be enacted independently of broader reforms.

There is no simple solution for the system in general, or for the specific issues faced by workingage people with disabilities. It seems clear, however, that reforms to benefit the latter will need to address some or all of the three major problems identified above. That is, reforms need to: reduce inefficient fragmentation of payers and improve coordination of financing; increase the priority for expenditures that help people with disabilities live and work in the community; and reduce or eliminate employment status as a determinant of coverage.

There have been some recent efforts to improve health care financing for working-age people with disabilities. The Medicaid Buy-in programs for people with disabilities attempt to break the link between employment and Medicaid eligibility, and have done so successfully in a number of states (Goodman and Livermore 2004). CMS has established Special Needs Plans that offer coordinated care to Medicare beneficiaries with chronic and disabling conditions and can integrate Medicare and Medicaid services for those eligible for both programs (Medicare Modernization Act of 2003). There has also been an increased interest in health promotion and chronic disease prevention on the part of the federal and state governments, as well as by employers attempting to address rising health care costs (O’Donnell 2006).

The Money Follows the Person initiative for Medicaid financing of long-term care represents an innovative approach for the financing of supports for low-income people with disabilities who are at-risk for living in long-term care facilities. In 2003, CMS awarded grants to nine states, as part of the New Freedom Initiative, to develop a system of flexible financing for long-term services and supports that enables available funds to move with the individual to the most appropriate and preferred setting as the individual's needs and preferences change (Anderson, Weiner and O’Keefe, 2006). These states are experimenting with approaches that both integrate funding from multiple social sources and more closely align spending decisions with the interests

\footnotetext{
${ }^{29}$ See Bound and Burkhauser, 1999; Stapleton and Tucker, 2000; Hill, Livermore and Houtenville, 2003; Autor and Duggan, 2003; and Autor and Duggan, 2006.
} 
of the individual. Although the target population includes only a small share of the working-age population with disabilities, the conceptual approach being tested can potentially be expanded to a broader population if it proves successful with this population.

These are all welcome developments, but small in comparison to the scope and complexity of the problems. They are not likely to meet the needs of most working-age people with significant long-term or permanent disabilities. A substantially higher percentage of working-age individuals will have such disabilities in the very near future. The combination of an aging Baby Boom generation and declining birth rates means that, in the next decade, a much larger share of the working-age population will be age 50 to 65 - the working-age group with the highest prevalence of disability, by far. The projected growth in the size of the population served, and projections of high growth in federal expenditures relative to revenues both make reforms to the maze that is our current system for financing health care and other services for working-age people with disabilities especially urgent. 


\section{REFERENCES}

Abbe, B. (2006). Overview - State High Risk Health Insurance Pools Today. MN: Communicating for Agriculture and the Self-Employed.

Americans with Disabilities Act of 1990, 42 U.S.C.A. §12101 et seq. (West 1993).

Anderson, G., \& Knickman, J.R. (2001). Changing the chronic care system to meet people's needs. Health Affairs. 20(6),146-161.

Anderson, W. L., J. M. Wiener and J.Keefe (2006) Money Follows the Person Initiatives of the Systems Change Grantees: Final Report. RTI International. http://www.cms.hhs.gov/RealChoice/ 12/18/06.

Appelbaum, P.S. (2003). The 'quiet' crisis in mental health services. Health Affairs. 22(5), 110.

Autor, D. \& Duggan, M. (2003). “The Rise in the Disability Rolls and the Decline in Unemployment.” Quarterly Journal of Economics, 118(1):157-206.

Autor, D. \& Duggan, M. (2006). "The Growth in the Social Security Disability Rolls: A Fiscal Crisis Unfolding.” The Journal of Economic Perspectives 20(3):71-96.

Bazelon Center for Mental Health Law (2003). Recovery in the community: Funding mental health rehabilitative approaches under Medicaid: Vol. 1. Washington DC: Bazelon Center.

Bianco, C., Hutchings, G., Behavioral, E.K., Kugler, R., Milstrey-Wells, S., Prialux, E., et al. (2001). Overcoming barriers to community integration for persons with mental illness. (Issue Brief). National Coalition to Promote Community-Based Care.

Bond, G.R (2004). Supported Employment: Evidence for and Evidence-Based Practice. Psychiatric Rehabilitation Journal. 27(4). 345-60.

Bound, J. \& Burkhauser, R. (1999). "Economic Analysis of Transfer Programs Targeted on People with Disabilities.” Chapter in the Handbook of Labor Economics, V. 3, eds. D. Card and O. Ashenfelter, pp. 3417-3528.

Burkhardt, J.E. (2002). Benefits of transportation services to health programs. Rockville, MD: WESTAT.

Centers for Medicare Advocacy (2006). Medicare Premiums and Deductibles for 2007. Press Retrieved January 15, 2007 http://www.medicareadvocacy.org/Medicare_2007Rates.htm

Center for Health Care Strategies (2006) Managed Care for People with Disabilities Purchasing Institute website. Accessed January 4, 2007. http://www.chcs.org/infourl_nocat3961/info-url_nocat_show.htm?doc_id=359008

Centers for Medicare and Medicaid Services (2005). 2003 CMS Statistics. Retrieved September, 2006, from http://www.cms.hhs.gov/CapMarketUpdates/Downloads/2005CMSStats.pdf

Centers for Medicare and Medicaid Services (2004). Medicaid Program: Real Choice Systems Change Grants, 2004 Solicitation Package. Retrieved January 2007 from http://www.cms.hhs.gov/RealChoice/downloads/2004Solicitation.pdf 
Congressional Budget Office (2005). The Potential Cost of Meeting Demand for Veterans' Health Care. Washington DC: Congressional Budget Office.

Chollet, D. (2002). Expanding individual health insurance coverage: Are high-risk pools the answer? Health Affairs Web Exclusive. Retrieved March, 2005, from http://content.healthaffairs.org/cgi/reprint/hlthaff.w2.349v1

Dale, S.B., \& Verdier, J.M. (2003). Elimination of Medicare's waiting period for seriously disabled adults: Impact on coverage and costs. (Issue Brief No. 660). Commonwealth Fund. Commonwealth Fund.

DeJong, G., Palsbo S.E., Beatty P.W., Jones G.C., Kroll T., \& Neri M.T. (2002). The organization and financing of health services for persons with disabilities. The Milbank Quarterly. 80(2), 261-301.

Delaware Assistive Technology Initiative (2005). Guide to Funding Resources for Assistive Technology in Delaware. Retrieved September 2006 from http://www.dati.org/funding/fundingTOC.html

Dembe, A.E. (2001). Access to medical care for occupational disorders: Difficulties and disparities. Journal of Health and Social Policy. 12(4), 19-33.

Dembe, A. E., Fox, S.E., \& Himmelstein, J.S. (2002). The RWJF workers' compensation health initiative: Findings and strategies. Health Affairs, 21(1), 251-255.

DiDonato, T. \& Brown, D. (2006). Workers compensation claim frequency down again in 2005. (Issue Brief). National Council on Compensation Insurance.

Eichner, J. and Blumenthal, D. (Eds.). (2003). Medicare in the $21^{\text {st }}$ Century: Building a better chronic care system. Washington, DC. National Academy of Social Insurance

Federal Register (2005) Federal Financial Participation in State Assistance Expenditures; Federal Matching Shares for Medicaid, the State Children's Health Insurance Program, and Aid to Needy Aged, Blind, or Disabled Persons for October 1, 2006 Through September 30, 2007 Vol. 70, No. 229 . Retrieved January 4, 2007. http://aspe.hhs.gov/health/fmap07.pdf

Foote, S.B., Wholey, D., Rockwood, T., \& Halpern, R. (2004). Resolving the tug-of-war between medicare's national and local coverage. Health Affairs. 23(4), 108.

Frank, R.G., Goldman, H.H., \& Hogan, M. (2003). Medicaid and mental health: Be careful what you ask for. Health Affairs. 22(1), 101.

Goodman, N. \& Livermore, G. (2004). The effectiveness of Medicaid buy-in programs in promoting the employment of people with disabilities. Social Security Administration, Ticket to Work and Work Incentives Advisory Panel. Retrieved April, 2005, from https://ssa.gov/work/panel/panel_documents/pdf_versions/Buyin\%20paper\%20Goodman_Livermore\%20072804r.pdf

Goodman, N. \& Stapleton, D.C. (2005). Program Expenditures for Working-age People with Disabilities in a Time of Fiscal Restraint: A Policy Brief. Ithaca, NY: Cornell University, Rehabilitation Research and Training Center for Economic Research on Employment Policy for People with Disabilities. 
Goodman, N. \& Stapleton, D.C. (in press). Federal program expenditures for working-age people with disabilities. Journal of Disability Policy Studies.

Gottlich, V. (2003, January). Medical necessity determinations in the Medicare program: Are the interests of beneficiaries with chronic conditions being met? Baltimore, MD Partnership for solutions: better lives for people with chronic conditions.

Greenspan, A. (2004). Economic outlook and current fiscal issues. Testimony before the Committee on the Budget, U.S. House of Representatives. February 25, 2004. Retrieved January 2007 from http://www.federalreserve.gov/boarddocs/testimony/2004/20040225/default.htm

Handleman, G.T. and Bruyere, S.M. (2000). Health Benefit Plans and the Americans with Disabilities Act. Ithaca, NY: Cornell University Employment and Disability Institute. Ithaca NY: Retrieved March, 2005, from http://digitalcommons.ilr.cornell.edu/edicollect/25

Hanson, K., Neumann, T. and Voris, M. (2003). Understanding the health care needs and experiences of people with disabilities: Findings from a 2003 survey. Kaiser Family Foundation. Retrieved February 6, 2004, from http://www.kff.org/medicare/loader.cfm?url=/commonspot/security/getfile.cfm\&PageID $=28401$

Harris Interactive Inc. (2004, June). 2004 Gaps Survey. New York.

Harrison, O. 2006. Employing People with Disabilities: Small Business Concerns and Recommendations. Boston MA: Institute for Community Inclusion. http://www.foremployers.com/index.php?page=icirp18

Hemp, R. \& Braddock, D. (2003). Ten questions on the role of Medicaid for persons with developmental disabilities in the United States. Working Paper. University of Colorado, Coleman Institute for Cognitive Disabilities.

Hill, S. C., Livermore, G. A., \& Houtenville, A. J. (2003). Rising health care expenditures and the employment of people with high cost chronic conditions. In D. C. Stapleton, \& R. V. Burkhauser (Eds.), The Decline in Employment of People with Disabilities: A Policy Puzzle (pp. 181-216). Kalamazoo, MI: W.E. Upjohn Institute.

Iezzoni, L.I., Davis, R.B., Soukup J., \& O'Day, B. (2003). Quality dimensions that most concern people with physical and sensory disabilities. Archives of Internal Medicine. 163(17), 2085-92.

Iezzoni, L.I., \& O'Day, B.L. (2006). More than ramps: a guide to improving health care quality and access for people with disabilities. New York: Oxford University Press.

Institute of Medicine (2001). Crossing the Quality Chasm: A New Health Care System for the $21^{\text {st }}$ Century. Washington DC: National Academy Press.

Ireys, H. T., Thornton, C., \& McKay, H. (2002). Medicaid managed care and working age beneficiaries with disabilities and chronic illnesses. Health Care Financing Review. 24(1), 27-42. 
Kaiser Family Foundation and Health Research and Educational Trust--Kaiser/HRET. (2003). Employer health benefits 2003 annual survey.

Kaiser Family Foundation and Health Research and Educational Trust--Kaiser/HRET. (2005). Employer health benefits 2005 annual survey.

Kaiser Family Foundation (2005). Medicaid Benefits: Online Database. http://www.kff.org/medicaid/benefits/

Kaiser Family Foundation. (2006). The Medicare prescription drug benefit. Fact Sheet.

Kaye, N. (2005). Medicaid managed care: Looking forward looking back. Portland, ME: National Academy of State Health Policy.

Lucia, K., \& Pollitz, K. (2004, April). Sumary of key consumer protections in individual health insurance markets. Georgetown University Health Policy Institute.

Lutterman, T., Hollen, V., \& Shaw, R. (2006). Funding sources and expenditure of state mental health agencies: Fiscal year 2001. National Association of State Mental Health Program Directors Research Institute. Retrieved January 15, 2007, from http://www.nriinc.org/reports_pubs/2006/RevExpenHighlights2004.pdf

Lutterman, T.; Yoe J.; Rivard, J.; Jacobs, R.; \& Thomas, N. (2006, February). Other state agency mental health services: Clients served expenditures. Presented to 16th Annual Conference on State Mental Health Agency Services Research, Program Evaluation, and Policy Research to Inform the System Transformation Process. Baltimore, MD.

Martinez, T.E \& Burt, M.R. (2006) Impact of Permanent Supportive Housing on the Use of Acute Care Health Services by Homeless Adults. Psychiatric Services 57:992-999.

Medical Expenditure Panel Survey Household Component (MEPS-HC): 2003 [Data file]. Center for Financing, Access, and Cost Trends, Agency for Healthcare Research and Quality. Analysis performed by Steven C. Hill at the request of authors 1/5/2007.

Medicare Prescription Drug, Improvement, and Modernization Act of 2003. Public Law 108173.

Medpac. (2006). Databook Chart 6.2. Washington DC: Medpac.

National Association of State Medicaid Directors. (2002). Aged, blind, and disabled Medicaid eligibility survey. Retrieved April, 2005, from: http://www.nasmd.org/eligibility/results6.asp

National Center for Health Statistics (2006). Health, United States 2006. Retrieved January 15 2007 from http://www.cdc.gov/nchs/data/hus/hus06.pdf

National Conference of State legislatures. Retrieved March, 2005, from http://www.ncsl.org/programs/health/drugaid.htm

National Council on Disability. (2000). Federal policy barriers to assistive technology. Retrieved March, 2005, from http:/www.ncd.gov/newsroom/publications/2000/assisttechnology.htm

O’Donnell, M. (2006). How big is the health promotion market? Small but getting big, with Medicare leading the way. American Journal of Health Promotion. Sept/Oct 2006: iv. 
O'Keeffe, J., Hulbert, M., Wiener, J., Siebenaler, K., O'Keeffe, J., et al. (2004). Federal-funded systems change initiatives to expand home and community services. Gerontologist. 44, 428-428.

Pollitz, K., Richard S., \& Thomas, K. (2001). Kaiser Family Foundation. How accessible is individual health insurance for consumers in less-than perfect health? Retrieved March, 2005, from http://www.kff.org/insurance/upload/34145_1.pdf

Raphael, D. (2001). Medicaid transportation: Assuring access to health care--A primer for states, health plans, providers and advocates. Community Transportation Association of America. Retrieved August 13, 2004, from http://www.ctaa.org/data/report.pdf

Reester, H., Missmar, R., \& Tumlinson, A. (2004, April). Recent growth in medicaid home and community-based service waivers. Washington, DC: The Kaiser Commission on Medicaid and the Uninsured.

Regenstein, M., \& Schroer, C. (1998, December). Medicaid Managed Care for Persons with Disabilities: State Profiles. The Economic and Social Research Institute.

Riley, G.F. (2006) Health insurance and access to care among social Security Disability Insurance Beneficiaries during the Medicare Waiting Period. Inquiry 43: 222-230.

Rizzolo, M.C., Hemp, R., Braddock, D. \& Pomeranz-Essley, A. (2004) The State of the States in Developmental Disabilities. Washington DC: American Association on Mental Retardation.

Sengupta, I, Reno, V., \& Burton, J.F. (2006). Workers' Compensation: Benefits, coverage, and costs, 2004. Washington, DC: National Academy of Social Insurance.

Singer, S. J. \& Bergthold, L.A. (2002). Prospects for improved decision making about medical necessity. Health Affairs. 20(1),23-29.

Social Security Act XVIII, 42 U.S.C.A. § 1395y et seq.

Social Security Amendments of 1972. Pub. L. No. 106-554, § 2991 (1972).

Sommers, A., Ghosh, A., \& Rousseau, D. (2005, June). Medicaid enrollment and spending by "mandatory" and "optional” eligibility and benefit categories. Washington, DC: The Kaiser Commission on Medicaid and the Uninsured.

Stapleton, D.C. (2004, April). The eligibility definition used in the Social Security Administration's disability programs needs to be changed. Presented at the Social Security Advisory Board's Discussion Forum on the Definition of Disability, Washington, DC.

Stapleton, D.C, O’Day, B.L, Livermore, G.A. \& Imparato, A.J. (2006). Dismantling the Poverty Trap: Disability Policy for the Twenty-First Century. Milbank Quarterly. 84(4): 701732.

Stapleton, D. and A. Tucker (2000) "Will Expanding Health Care Coverage for People with Disabilities Increase Their Employment and Earnings? Evidence from an Analysis of the SSI Work Incentive Program," in Research in Human Capital and Development, Vol. 13, pages 133-180, Stamford, CT: JAI Press. 
Stegman, M.A. (2002, Summer). Fall and Rise of Public Housing. Regulation Magazine: The Cato Review of Business and Government. 64-70.

Steinmetz, E. (2006, May). Americans with Disabilities: 2002 Household Economic Studies. Current Population Reports P70-10. Washington, DC : U.S. Bureau of the Census.

Technical Assistance Collaborative (n.d). Section 811 Supportive Housing for Persons with Disabilities (Section 811). Retrieved January 2007. http://www.tacinc.org/HH/Program_Policy/Section811.htm

Ticket to Work and Work Incentives Improvement Act of 1999. Pub. L. No. 106-170 § 2 (1999).

United States Department of Health and Human Services, Health Resources and Services Administration. (n.d.) Retrieved March, 2005, from www.hrsa.gov/.

United States Department of Labor, Employee Benefits Security Administration (2005). An employee's guide to health benefits under COBRA: The Consolidated Omnibus Budget Reconciliation Act of 1986. Retrieved September 28, 2006, from http://www.dol.gov/ebsa/pdf/cobraemployee.pdf

United States Government Accountability Office. (2000). Mental health parity act: Employers' mental health benefits remain limited despite new federal standards. (Publication No. GAO/T-HEHS-00-113).

United States Government Accountability Office. (2003a). Medicaid and Ticket to Work: State's early efforts to cover working people with disabilities. (Publication No. GAO-03-587).

United States Government Accountability Office. (2003b). Long-term care: Federal oversight of growing Medicaid home and community-base waivers should be strengthened. (Publication No. GAO-03-576).

United States Government Accountability Office. (2003c). Medicaid formula: differences in funding ability among states are often widened. (Publication No.GAO-03-620).

United We Ride (u.d.). Retrieved March, 2005, from http://www.unitedweride.gov/

University of Washington Center for Technology and Disability Studies.(2003). Paying for the assistive technology you need: A consumer guide to funding sources in Washington state. Retrieved August 10, 2004, from http://uwctds.washington.edu/funding\%20manual/index.htm\#begin

United States Department of Veterans Affairs. (n.d.a). Health care eligibility: All enrollment priority groups. Retrieved April, 2005, from http://www.va.gov/healtheligibility/eligibility/PriorityGroupsAll.asp

United States Department of Veterans Affairs. (n.d.b). VA Programs for Homeless Veterans. Retrieved September , 2006, from http://www1.va.gov/homeless/

Veterans Affairs Information Resource Center. (2003). Veterans' enrollment, access and use of Medicare and VA health services: Report to the under Secretary for Health. Retrieved May 1, 2005, from http://www.hsrd.research.va.gov/research/abstracts.cfm?Project_ID=260875094 
Vladeck, Bruce C (2001). You can't get there from here: Obstacles to improving care of the chronically ill. Health Affairs. 20(6),175-180.

Work World. (n.d.) Retrieved March, 2005, from, from http://workworld.org 
For more information about the Cornell RRTC contact:

Susanne M. Bruyère, Ph.D., CRC

Project Director

201 ILR Extension Building

Cornell University

Ithaca, NY 14853-3901 tel (607) 255-9536

fax (607) 255-2763

TDD (607) 255-2891

e-mailssmb23@cornell.edu

web www.ilr.cornell.edu/rrtc 